\title{
A ictiofauna do Canal de Bertioga, São Paulo, Brasil
}

\author{
Bruno Barbanti' ${ }^{1}$ Rodrigo Caires $^{2} \&$ Alexandre Pires Marceniuk $^{1,3,4}$ \\ ${ }^{1}$ Núcleo Integrado de Biotecnologia, Laboratório de Genética de Organismos Aquáticos e Aquicultura, \\ Universidade de Mogi das Cruzes - UMC, CP 411, CEP 08701-970, Mogi das Cruzes, SP, Brasil \\ www.umc.br \\ ${ }^{2}$ Museu de Zoologia, Universidade de São Paulo - USP, CP 42494, CEP 04218-970, São Paulo, SP, Brasil \\ ${ }^{3}$ Instituto de Estudos Costeiros, Universidade Federal do Pará - UFPA, Alameda Leandro Ribeiro, \\ CEP 68600-000, Bragança, PA, Brasil \\ ${ }^{4}$ Autor para correspondência: Alexandre Pires Marceniuk, e-mail: a_marceniuk@hotmail.com
}

BARBANTI, B., CAIRES, R. \& MARCENIUK, A.P. The ichthyofauna of the Bertioga Channel, São Paulo, Brazil. Biota Neotrop. 13(1): http://www.biotaneotropica.org.br/v13n1/en/abstract?inventory+bn02913012013

\begin{abstract}
The Bertioga Channel, on the coast of the São Paulo state, is delimited by the continental shore and the island of Santo Amaro, and represents a secondary connection of the Santos-São Vicente estuarine complex to the ocean and adjoins the municipalities of Santos, Guarujá and Bertioga. In the present study collections were made between December 2009 and November 2010 in the northern stretch of the Bertioga Channel (23 51' 23,83”' S, $46^{\circ} 07^{\prime} 58,87^{\prime \prime}$ W to $23^{\circ} 53^{\prime} 31,72^{\prime}$ S, $46^{\circ} 11^{\prime} 17,74^{\prime \prime} \mathrm{W}$ ) in order to provide an inventory of the ichthyofauna of the region. A total of 1,429 specimens were collected, belonging to 78 species, 67 genera, 39 families and 14 orders. The most species rich families were Sciaenidae (nine spp.), Carangidae (nine spp.), Haemulidae (seven spp.), and Ariidae (five spp.). The most abundant species were Stellifer rastrifer $(\mathrm{n}=243)$, Harengula clupeola $(\mathrm{n}=182)$, Cathorops spixii $(\mathrm{n}=144)$, Oligoplites palometa $(\mathrm{n}=109)$ and Mugil curema $(\mathrm{n}=102)$. The species Achirus lineatus, Atherinella brasiliensis, Cathorops spixii, Chaetodipterus faber, Citharichthys spilopterus, Genidens genidens, Micropogonias furnieri and Stellifer rastrifer, were collected in all seasons of the year. Of the species encountered, six were considered constant, 19 accessorial and 53 occasional. In relation to habitat association, 40 species are marine-estuarine, 26 species marine, 11 species estuarine and one species freshwater, being 52 demersal species and 26 pelagic species. Eleven species are included in red lists. Additionally, an identification key to the species of the northern stretch of the Bertioga Channel is presented.
\end{abstract}

Keywords: Estuary, biodiversity, conservation, identification key, Santos-São Vicente estuarine complex.

BARBANTI, B., CAIRES, R. \& MARCENIUK, A.P. A ictiofauna do Canal de Bertioga, São Paulo, Brasil. Biota Neotrop. 13(1): http://www.biotaneotropica.org.br/v13n1/pt/abstract?inventory+bn02913012013

Resumo: O Canal de Bertioga, localizado no litoral do estado de São Paulo, é delimitado pelo continente e pela ilha de Santo Amaro, constituindo a unidade natural que conecta os municípios de Santos, Guarujá e Bertioga, representando uma segunda conexão do complexo estuarino de Santos-São Vicente com o oceano. No presente estudo foram realizadas coletas, entre dezembro de 2009 a novembro de 2010, no trecho norte do

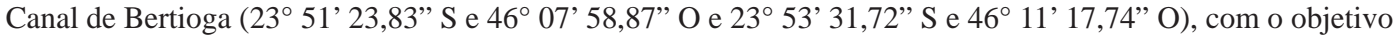
de inventariar a ictiofauna da região. Foram coletados 1.429 exemplares, pertencentes a 78 espécies, incluídas em 14 ordens, 39 famílias e 67 gêneros. As famílias mais especiosas foram Sciaenidae (nove spp.), Carangidae (nove spp.), Haemulidae (sete spp.), e Ariidae (cinco spp.), e as espécies mais abundantes foram Stellifer rastrifer $(\mathrm{n}=243)$, Harengula clupeola $(\mathrm{n}=182)$, Cathorops spixii $(\mathrm{n}=144)$, Oligoplites palometa $(\mathrm{n}=109)$ e Mugil curema (n =102), sendo que Achirus lineatus, Atherinella brasiliensis, Cathorops spixii, Chaetodipterus faber, Citharichthys spilopterus, Genidens genidens, Micropogonias furnieri e Stellifer rastrifer, ocorreram em todas estações do ano. Das espécies encontradas, seis foram reconhecidas constantes, 19 acessórias e 53 ocasionais. Em relação aos seus hábitos, 40 espécies são marinho-estuarinas, 26 marinhas, 11 estuarinas e uma de água doce, sendo 52 espécies demersais e 26 pelágicas. Onze espécies são relacionadas em listas de espécies ameaçadas. Adicionalmente, é apresentada uma chave de identificação para as espécies do trecho norte do Canal de Bertioga. Palavras-chaves: Estuário, biodiversidade, conservação, chave de identificação, complexo estuarino de SantosSão Vicente. 


\section{Introdução}

O Canal de Bertioga está inserido na porção norte da região metropolitana da Baixada Santista, litoral sul do estado de São Paulo (Figura 1), delimitado pelo continente e pela ilha de Santo Amaro (Bernardes 2001, Santos et al. 2007). Enquanto a desembocadura sul conecta o Canal de Bertioga ao complexo estuarino de Santos-São Vicente, a desembocadura norte representa uma segunda conexão do complexo estuarino com o oceano (Miranda et al. 1998). O Canal de Bertioga tem aproximadamente $25 \mathrm{~km}$ de extensão, largura média variando entre 200 a $700 \mathrm{~m}$, e profundidade média variando entre 3 a $6 \mathrm{~m}$, podendo atingir profundidades de até $12 \mathrm{~m}$, na confluência com os tributários (Miranda et al. 1998). Seu principal tributário é o rio Itapanhaú, com uma descarga fluvial média de aproximadamente $10 \mathrm{~m}^{3}$ s-1 (Miranda et al. 1998). A porção central, conhecida como Largo do Candinho, é resultado do encontro das correntes de maré provenientes da desembocadura norte e da desembocadura sul, formando o "tombo das águas", que serve como uma barreira para o fluxo das águas provenientes das porções norte e sul do canal (Bernardes 2001). O sistema biológico é o ecossistema de manguezal, com espécies vegetais adaptadas à grande variação de salinidade, e sedimentos lodosos, com baixo teor de oxigênio (Schaeffer-Novelli \& Cintron 1986, Schaeffer-Novelli 1991).

O estado de São Paulo está incluído na Província Zoogeográfica Argentina, que se estende de Cabo Frio, no estado do Rio de Janeiro, à Península de Valdés, na Argentina (Figueiredo 1981). Essa província é uma área de transição faunística, sofrendo a influência das águas quentes da Corrente do Brasil e das águas frias da Corrente das Malvinas, incluindo os extremos meridionais de distribuição de espécies tropicais e os extremos setentrionais de espécies temperadas, com cerca de 10\% de espécies endêmicas (Figueiredo 1981). A ictiofauna do estado de São Paulo é composta por espécies restritas à Província Argentina, quanto por espécies com ampla distribuição no Atlântico, ou em outros oceanos. Segundo Castro \& Menezes (1998), a ictiofauna marinha do estado de São Paulo é bem conhecida e sua taxonomia confiável, sendo citadas para região cerca de 512 espécies de peixes, pertencentes a 32 ordens e 120 famílias, com uma parcela delas apresentando parte do ciclo de vida associado a sistemas

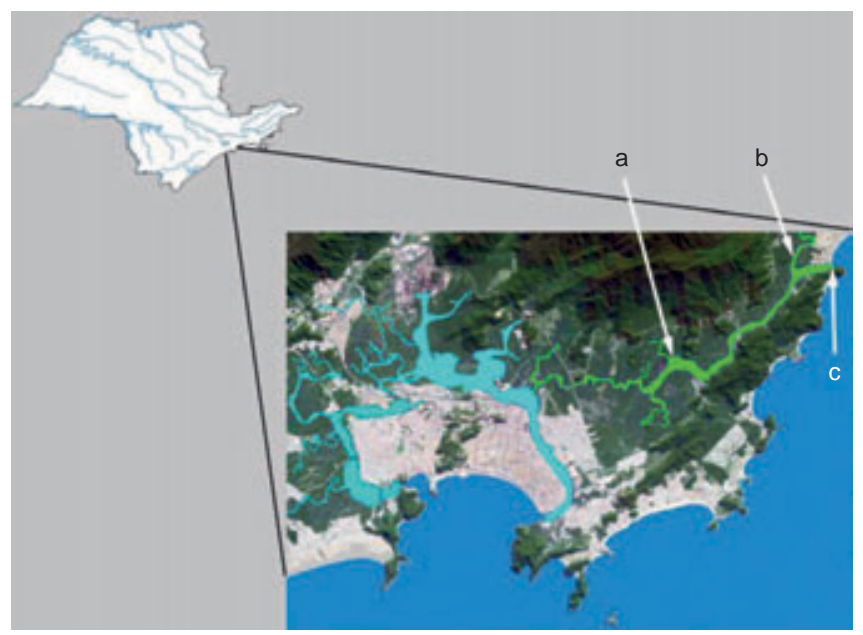

Figura 1. Complexo estuarino de Santos-São Vicente (verde claro) e Canal de Bertioga em destaque (verde escuro). A. Largo do Candinho; B. rio Itapanhaú; C. barra do canal.

Figure 1. The estuarine complex of Santos-São Vicente (light green), and the Bertioga Channel highlighted (dark green). A. Largo do Candinho; B. Itapanhaú river; C. mouth of the Bertioga Channel. estuarinos (Carvalho-Filho 1999, Figueiredo \& Menezes 1978, 1980, 2000, Menezes \& Figueiredo 1980, 1985).

O complexo estuarino de Santos-São Vicente é considerado um dos maiores criadouros naturais de peixes da região sudeste do Brasil (Paiva-Filho et al. 1987). O primeiro levantamento da ictiofauna do complexo estuarino de Santos-São Vicente foi realizado por Luederwaldt (1919), enquanto desde o final da década de 60 diversos estudos abordaram aspectos da pesca, ecologia e biologia das espécies encontradas na região (Puzzi \& Silva 1981, Paiva-Filho 1982, Goitein 1984, Goitein \& Mesquita Filho 1985, Puzzi et al. 1985, PaivaFilho et al. 1986, Giannini \& Paiva-Filho 1990, 1992, 1995, Paiva Filho \& Giannini 1990, Fundação... 1991, Fagundes et al. 2007), com menor número de trabalhos de inventariamento (Vazzoler 1969, Paiva-Filho 1982, Paiva-Filho \& Toscano 1987, Giannini \& PaivaFilho 1990, Fundação... 2006). Trabalhos de inventariamento da ictiofauna do trecho sul do Canal de Bertioga foram realizados pela Fundação... (1991) e de Rocha (2009), no entanto, faltam estudos a respeito da ictiofauna do trecho norte do Canal de Bertioga.

O presente trabalho tem como objetivo o inventariamento da ictiofauna do trecho norte do Canal de Bertioga, com dados de distribuição e abundância das espécies nas diferentes épocas do ano e diferentes ambientes amostrados, e a documentação fotográfica das espécies e das localidades de coleta. Complementarmente, é apresentada uma chave de identificação para as espécies da região.

\section{Material e Métodos}

A área de estudo abrangeu a porção norte do Canal de Bertioga, entre a barra do canal, em Bertioga e Guarujá ( $23^{\circ}$ 51' 23,83” S e

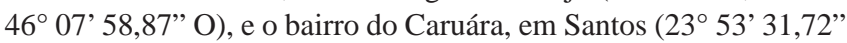
S e $46^{\circ} 11^{\prime} 17,74^{\prime \prime}$ O) (Figura 1 ). As coletas tiveram como objetivo amostrar o maior número possível de espécies nestas áreas, realizadas com licença do IBAMA, número 22841-1. Pescadores profissionais da Colônia de Pescadores Z-23 (Bertioga), colaboraram com informações a respeito das características ambientais da região e das diferentes espécies de peixes existentes na região. Coletas mensais foram realizadas entre dezembro de 2009 e novembro de 2010, em três áreas amostrais com características ambientais distintas, a primeira na porção mais interna do trecho norte Canal de Bertioga (área 1, 23 53’ 28,73” S e 46 11’ 05,63” O) (Figura 2b), a segunda na confluência do rio Itapanhaú com o Canal de Bertioga (área 2, $23^{\circ}$ 51'32,11” S e 4609' 17,03”' O) (Figura 2c), e a terceira no limite norte, próximo à boca da barra (área $3,23^{\circ} 51^{\prime}$ 24,33” S e $46^{\circ} 51^{\prime}$ 24,33” O) (Figura 2a). Na área 1 foram utilizadas quatro técnicas diferentes de coleta: rede de arrasto manual tipo picaré (Figura 2d), com $4 \mathrm{~m}$ de comprimento por $2 \mathrm{~m}$ de altura e malha de $10 \mathrm{~mm}$ entre nós opostos; rede de espera (emalhe), com $100 \mathrm{~m}$ de comprimento por $4 \mathrm{~m}$ de altura e malha de 70 mm entre nós opostos; a mesma rede foi utilizada na forma de caceio; rede de arrasto de fundo com portas, com boca de $3 \mathrm{~m}$ e malha de 30 mm entre nós opostos. Na área 2 e 3 foram utilizadas as mesma técnicas descritas para área 1. Somente na área 3, diferentes técnicas de coleta foram utilizadas devido às características ambientais encontradas na área, sendo também utilizada: tarrafa, com raio de $2 \mathrm{~m}$ e malha de $40 \mathrm{~mm}$ entre nos opostos; covo com isca, confeccionado com malha de $30 \mathrm{~mm}, 1 \mathrm{~m}$ de altura por um metro e meio de comprimento; espinhel de anzóis com 80 m e 25 anzóis de aço com farpa simples entre 1,5 a $7 \mathrm{~cm}$; e pesca com linha de mão. Os parâmetros físico-químicos dos pontos de coletas foram registrados com objetivo de caracterizar a área de estudo, através da sonda multiparâmetro da marca HANNA, calibração e certificação da ISO NBR. Os parâmetros avaliados foram o potencial de hidrogênio $(\mathrm{pH})$, oxigênio dissolvido (OD), salinidade e temperatura. O estádio 

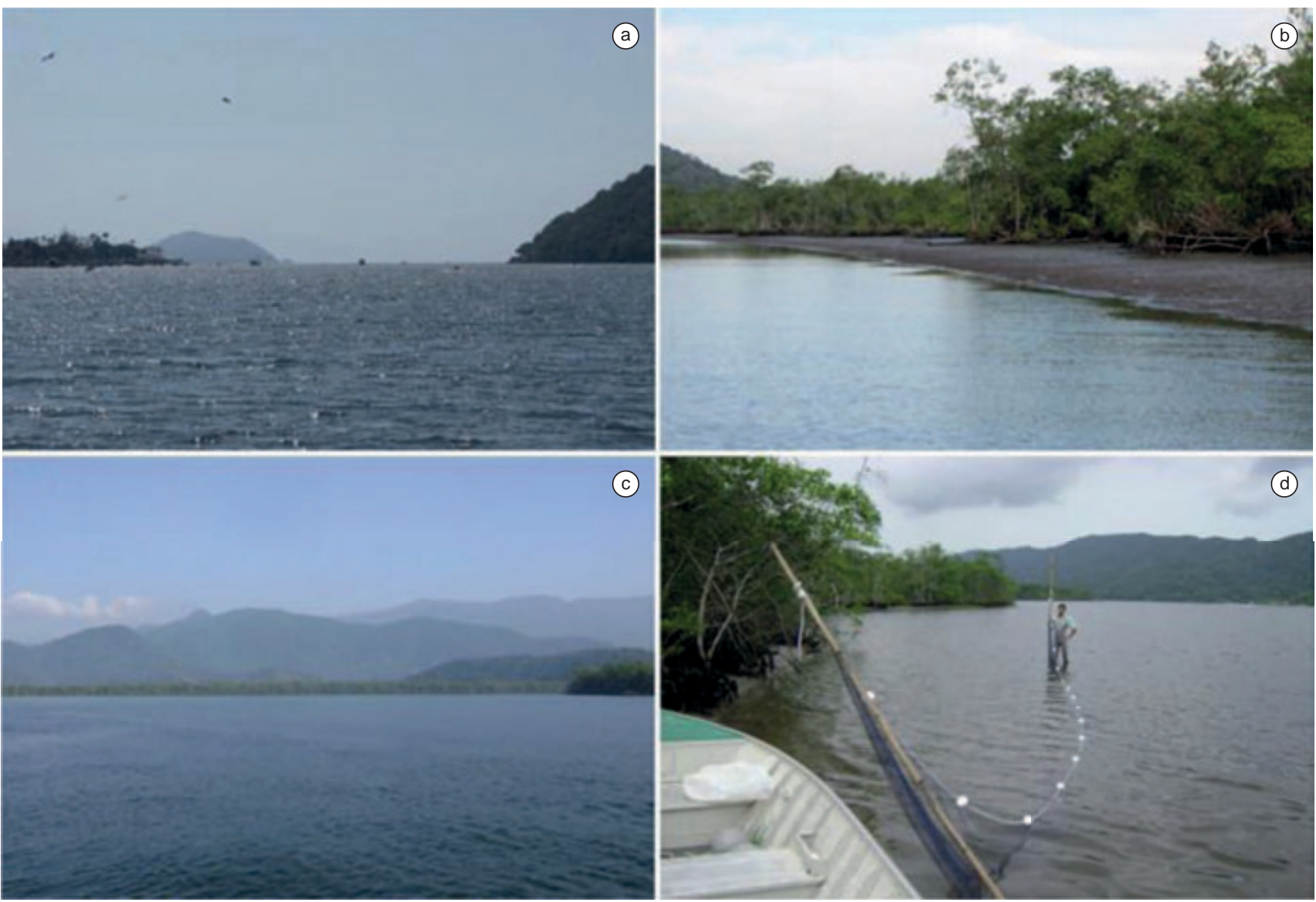

Figura 2. Trecho norte do Canal de Bertioga: (a) barra do Canal de Bertioga (área 3); (b) praia lamosa na porção mais interna do canal (área 1); (c) confluência com o rio Itapanhaú (área 2); (d) coleta com picaré em praia arenosa (área 1).

Figure 2. Northern stretch of the Bertioga Channel: (a) mouth of the Bertioga Channel (area 3); (b) muddy shore of innermost portion of the Bertioga Channel (area 1); (c) confluent with Itapanhaú River (area 2); (d) seine net collection on sandy shore (area 1).

de maturação dos exemplares foi determinado através de exame das gônadas sob microscópio estereoscópico

As espécies foram identificadas com base nas descrições e chaves de identificação propostas por Figueiredo \& Menezes (1978, 1980 e 2000), Menezes \& Figueiredo (1980, 1985), Food... (2003) e Marceniuk (2005), assim como através da comparação com exemplares da coleção ictiológica do Museu de Zoologia da USP. A nomenclatura adotada seguiu Menezes et al. (2003) e Eschmeyer (2011). A eficiência do esforço amostral foi avaliada pela curva de acumulação, ou curva do coletor, (Palmer 1990, Colwell et al. 2004), através dos estimadores de riqueza Jacknife1, Jacknife2, Bootstrap, Michaelis Menton e UGE (Colwell \& Coddington 1994). As espécies foram classificadas como constantes, acessórias ou ocasionais, com base na freqüência de ocorrência (respectivamente, igual ou maior que $50 \%$, igual ou maior que $25 \%$, e menor que $25 \%$ ), calculada segundo Dajoz (1973). A diversidade e abundância das espécies no trecho norte do Canal de Bertioga foi determinada pela aplicação dos índices de diversidade de Shannon-Wiener e riqueza de espécies de Margalef. O cálculo dos diferentes índices e curvas foram realizados pelo programa Primer 6.0 (Primer-E 2004).

$\mathrm{Na}$ tabela e nas figuras, a sequência das ordens, famílias e subfamílias, seguem a classificação evolutiva adotada por Eschmeyer (2011), enquanto os gêneros e espécies estão em ordem alfabética dentro de cada família. As espécies são reconhecidas como marinhas, estuarinas e marinha-estuarinas com base em Figueiredo \& Menezes
(1978, 1980, 2000), e Menezes \& Figueiredo (1980, 1985). As espécies com algum grau de ameaça são aquelas incluídas na lista da fauna ameaçada de extinção do estado de São Paulo (São Paulo 2009). Exemplares representativos de cada uma das espécies coletadas foram depositados na coleção Zoológica do Laboratório de Biologia e Genética de Peixes da Universidade Estadual Paulista em Botucatu (LBP), com amostras de tecido dos exemplares depositados na mesma coleção (Anexo I).

\section{Resultados}

Foram inventariadas 78 espécies de Teleósteos no trecho norte do Canal de Bertioga (Figuras 3, 4, 5), distribuídos em 14 ordens e 39 famílias, com 1.429 exemplares coletados (Tabela 1). A curva do coletor atingiu a assintota, com a riqueza total de espécies obtida ao termino esforço amostragem (Figura 6). Representantes da classe Chondrichthyes não foram coletados.

As ordens com maior número de representantes foram Perciformes (49 spp.), Siluriformes (6 spp.), Tetraodontiformes (5 spp.), e Clupeiformes (quatro spp.). As famílias com maior riqueza de espécies foram Carangidae (nove spp.), Sciaenidae (nove spp.), Haemulidae (sete spp.), e Ariidae (cinco spp.). As espécies mais abundantes foram Stellifer rastrifer $(\mathrm{n}=243)$, Harengula clupeola $(\mathrm{n}=182)$, Cathorops spixii $(\mathrm{n}=144)$, Oligoplites palometa ( $\mathrm{n}=109)$, Mugil curema $(\mathrm{n}=102)$, Citharichthys spilopterus $(\mathrm{n}=90)$, Atherinella brasiliensis $(\mathrm{n}=65)$, Diapterus rhombeus $(\mathrm{n}=60)$, 


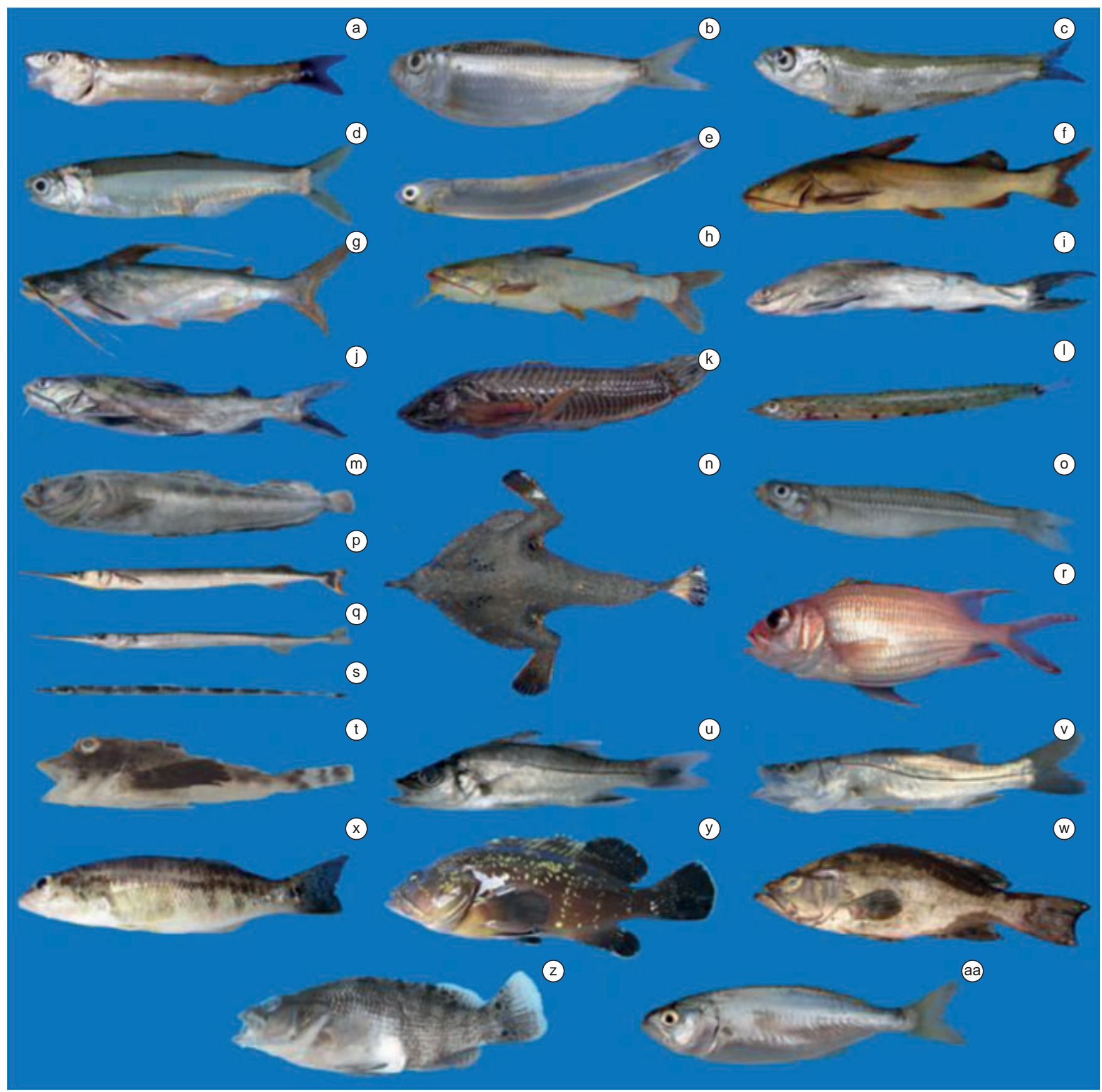

Figura 3. Espécies de peixes das ordens Clupeiformes, Siluriformes, Aulopiformes, Batrachoidiformes, Lophiiformes, Atheriniformes, Beloniformes, Beryciformes, Syngnathiformes, Scorpaeniformes e Perciformes, do Canal de Bertioga.

Figure 3. Fish species of the orders Clupeiformes, Siluriformes, Aulopiformes, Batrachoidiformes, Lophiiformes, Atheriniformes, Beloniformes, Beryciformes, Syngnathiformes, Scorpaeniformes, and Perciformes, from the Bertioga Channel.

Albulidae: (a) Albula vulpes, exemplar não preservado, 36 mm CT. Clupeidae: (b) Harengula clupeola, LBP 10064, 92 mm CT; (c) Sardinella brasiliensis, exemplar não preservado, 46 mm CT. Engraulidae: (d) Lycengraulis grossidens, LBP 10065, 134 mm CT; (e) Anchoviella lepidentostole, exemplar não preservado, 35 mm CT. Ariidae: (f) Aspistor luniscutis, LBP 40502, 214 mm CT; (g) Bagre bagre, LBP 40597, 372 mm CT; (h) Cathorops spixii, LBP 40605 , 276 mm CT; (i) Genidens barbus, exemplar não preservado, 130 mm CT; (j) Genidens genidens, LBP 10038, 110 mm CT. Callichthyidae: (k) Callichthys callichthys, exemplar não preservado, 116 mm CT. Synodontidae: (l) Synodus foetens, exemplar não preservado, 38 mm CT. Batrachoididae: (m) Porichthys porosissimus, LBP 10034, 285 mm CT. Ogcocephalidae: (n) Ogcocephalus vespertilio, exemplar não preservado, 174 mm CT. Atherinopsidae: (o) Atherinella brasiliensis, LBP 40562 , 109 mm CT. Belonidae: (p) Strongylura marina, exemplar não preservado, 590 mm CT; (q) Strongylura timucu, LBP 10057, 214 mm CT. Holocentridae: (r) Holocentrus adscensionis, exemplar não preservado, 156 mm CT. Syngnathidae: (s) Syngnathus folletti, não preservado, 173 mm CT. Triglidae: (t) Prionotus punctatus, LBP 10084, 85 mm CT. Centropomidae: (u) Centropomus parallelus, LBP 40501, 137 mm CT; (v) Centropomus undecimalis, LBP 40602 , 284 mm CT. Serranidae: (x) Diplectrum radiale, LBP 10069, 124 mm CT; (y) Epinephelus marginatus, não preservado, 174 mm CT; (w) Mycteroperca acutirostris, não preservado, 322 mm CT; (z) Serranus flaviventris, LBP 10079, 101 mm CT. Pomatomidae: (aa) Pomatomus saltatrix, LBP 10082,78 mm CT. 


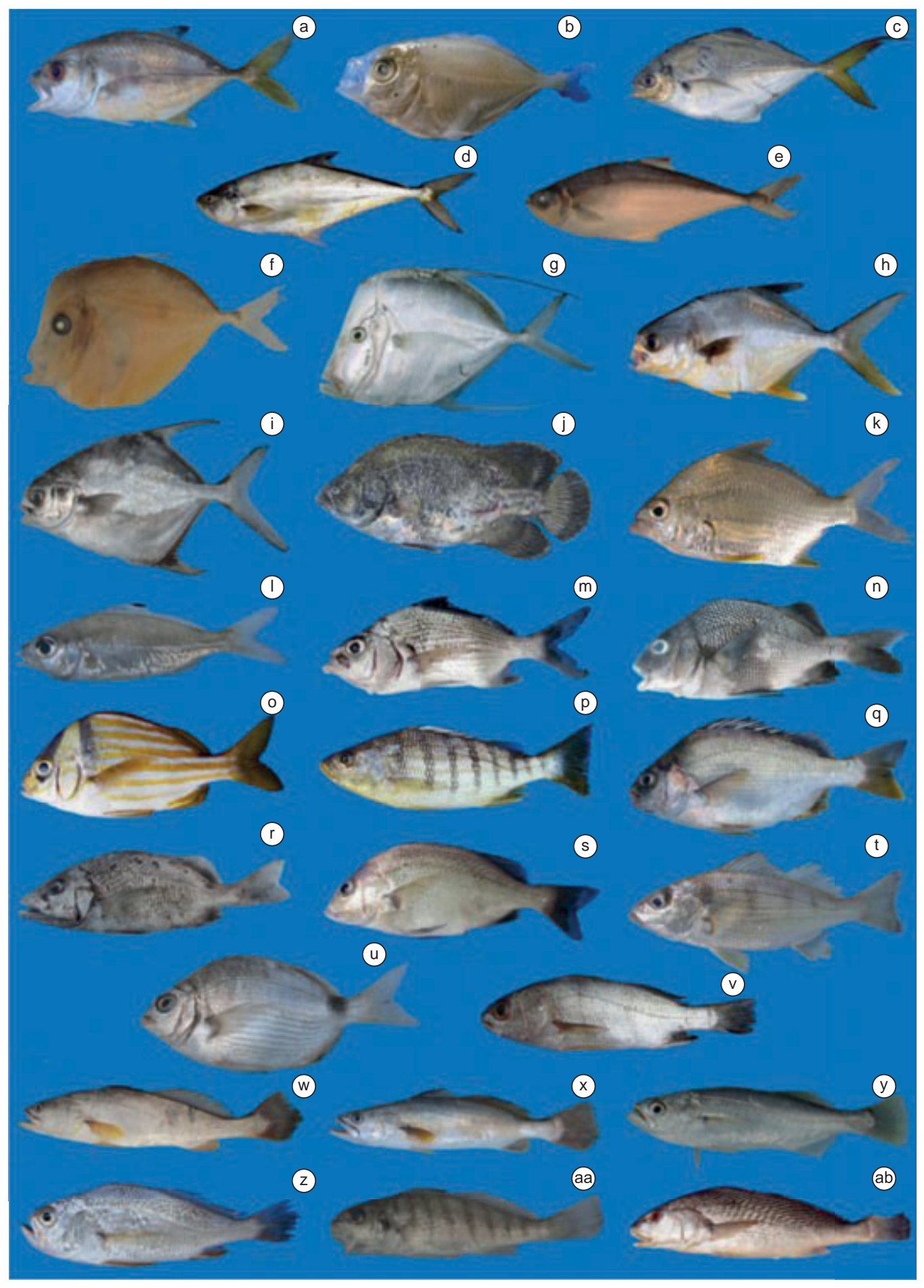

Figura 4. Espécies de peixes da ordem Perciformes (continuação), do Canal de Bertioga.

Figure 4. Fish species of the orders Perciformes (continued), from the Bertioga Channel.

Carangidae: (a) Caranx latus, LBP 40535, 11,4 mm CT; (b) Chloroscombrus chrysurus, exemplar não preservado, 34 mm CT; (c) Hemicaranx amblyrhynchus, LBP 10054, 287 mm CT; (d) Oligoplites palometa, LBP 10053, 298 mm CT; (e) Oligoplites saliens, exemplar não preservado, 313 mm CT; (f) Selene setapinnis, LBP 10083, 46 mm CT; (g) Selene vomer, LBP 10046, 35 mm CT; (h) Trachinotus carolinus, LBP 10067, 235 mm CT; (i) Trachinotus falcatus, LBP 1044, 278 mm CT. Lobotidae: (j) Lobotes surinamensis, LBP 10052, 35 mm CT. Gerreidae: (k) Diapterus rhombeus, LBP 10078, 140 mm CT; (l) Eucinostomus melanopterus, não preservado, 84 mm CT; (m) Eugerres brasilianus, exemplar não preservado, 250 mm CT. Haemulidae: (n) Anisotremus surinamensis, LBP 10059, 250 mm CT; (o) Anisotremus virginicus, exemplar não preservado, 190 mm CT; (p) Conodon nobilis, exemplar não preservado, 196 mm CT; (q) Genyatremus luteus, LBP 10033, 267 mm CT; (r) Haemulon steindachneri, LBP 10058, 298 mm CT; (s) Orthopristis ruber, exemplar não preservado, 197 mm CT; (t) Pomadasys corvinaeformis, exemplar não preservado, 126 mm CT. Sparidae: (u) Diplodus argenteus, LBP 10068, 221 mm CT. Sciaenidae: (v) Bardiella ronchus, LBP 40524, 123 mm CT; (w) Cynoscion acoupa, LBP 40599, 390 mm CT; (x) Cynoscion microlepidotus, LBP 40588,378 mm CT; (y) Isopisthus parvipinnis, LBP 10072, 194 mm CT; (z) Larimus breviceps, exemplar não preservado, 115 mm CT; (aa) Menticirrhus americanus, LBP 10073, 165 mm CT; (ab) Micropogonias furnieri, LBP 10070, 340 mm CT. 


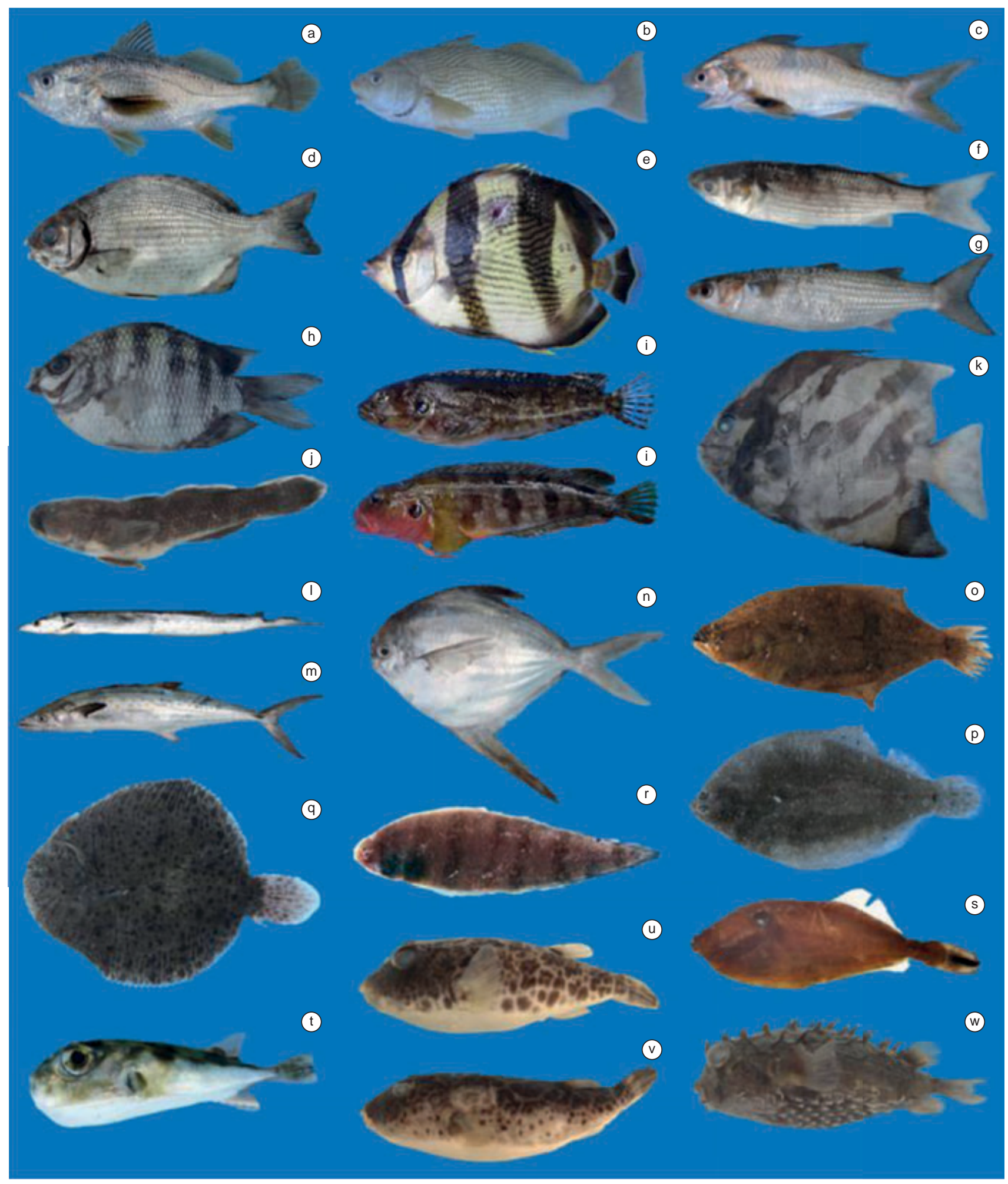

Figura 5. Espécies de peixes das ordens Perciformes (continuação), Pleuronectiformes e Tetraodontiformes, do Canal de Bertioga. Figure 5. Fish species of the orders Perciformes (continued), Pleuronectiformes and Tetraodontiformes, from the Bertioga Channel.

Perciformes: (a) Stellifer rastrifer, LBP 10074, 117 mm CT; (b) Umbrina coroides, exemplar não preservado, 304 mm CT. Polynemidae: (c) Polydactylus virginicus, LBP 1060, 35 mm CT. Kyphosidae: (d) Kyphosus saltatrix, LBP 10048, 314 mm CT. Chaetodontidae: (e) Chaetodon striatus, exemplar não preservado, 201 mm CT. Mugilidae: (f) Mugil curema, LBP 10004, 143 mm CT; (e) Mugil liza, LBP 10051, 310 mm CT. Pomacentridae: (h) Abudefduf saxatilis, LBP 40579,135 mm CT. Labrisomidae: (i) Labrisomus nuchippinis, exemplar não preservado 185 mm CT. Gobiidae: (j) Bathygobius soporator, LBP 40568,114 mm CT. Ephippidae: (k) Chaetodipterus faber, LBP 40510, 142 mm CT. Trichiuridae: (l) Trichiurus lepturus, LBP 10036, 493 mm CT. Scombridae: (m) Scomberomorus brasiliensis, LBP 10035, 415 mm CT. Stromateidae: (n) Peprilus paru, LBP 10045, 188 mm CT. Paralichthyidae: (o) Citharichthys spilopterus, LBP 40505, 125 mm CT; (p) Etropus crossotus, LBP 10088, 96 mm CT. Achiridae: (q) Achirus lineatus, LBP 40512, 114 CT. Cynoglossidae: (r) Symphurus tesselatus, LBP 10076, 135 mm CT. Monacanthidae: (s) Aluterus monoceros, LBP 40534, 253 mm CT. Tetraodontidae: (t) Lagocephalus laevigatus, LBP 10087, 61 mm CT; (u) Sphoeroides greeleyi, LBP 10086, 93 mm CT; (v) Sphoeroides testudineus, LBP 10062, 120 mm CT. Diodontidae: (w) Chilomycterus spinosus, LBP 40572,135 mm CT. 
Tabela 1. Ictiofauna do trecho norte do Canal de Bertioga. A. Número de exemplares, com comprimento máximo e mínimo em milímetros. B. Espécies com algum grau de ameaça segundo a Fauna Ameaçada de Extinção no Estado de São Paulo: sobrexplotada (SE); ameaçada de sobrexplotação (AS). C. Freqüência de ocorrência: constantes (C); acessórias (A); ocassionais (O). D. Hábitos de vida: demersal (D); pelágico (P). E. Habitats preferenciais: água doce (AD); estuarino (E); marinho (M); marinho-estuarino (ME).

Table 1. Ichthyofauna of the northern stretch of the Bertioga Channel. A. Number of individuals, with maximum and minimum sizes in millimeters. B. Species under some degree of risk of extinction according to the São Paulo state Threatened Species List: overexploited (SE); threatened with overexploitation (AS). C. Frequency of occurrence: constant (C); accessorial (A); occasional (O). D. Lifestyle: demersal (D), pelagic (P). E. Habitat preference: freshwater (AD); estuarine (E); marine (M); marine-estuarine (ME).

\begin{tabular}{|c|c|c|c|c|c|c|c|c|}
\hline Ordem & Família & Subfamília & Espécie & $\mathbf{A}$ & B & $\mathbf{C}$ & $\mathbf{D}$ & $\mathbf{E}$ \\
\hline Albuliformes & Albulidae & Albulinae & Albula vulpes (Linnaeus 1758) & $2(50-50)$ & & $\mathrm{O}$ & $\mathrm{P}$ & $\mathrm{M}$ \\
\hline \multirow[t]{4}{*}{ Clupeiformes } & Clupeidae & & Harengula clupeola (Cuvier 1829) & $182(42-180)$ & & A & $\mathrm{P}$ & $\mathrm{M}$ \\
\hline & & & Sardinella brasiliensis (Steindachner 1879) & $1(46)$ & SE & $\mathrm{O}$ & $\mathrm{P}$ & M \\
\hline & Engraulidae & & Lycengraulis grossidens (Spix \& Agassiz 1829) & $4(110-146)$ & & A & $\mathrm{P}$ & M \\
\hline & & & Anchoviella lepidentosteo (Fowler 1911) & $58(21-41)$ & & $\mathrm{O}$ & $\mathrm{P}$ & $\mathrm{M}$ \\
\hline \multirow[t]{6}{*}{ Siluriformes } & Ariidae & & Aspistor luniscutis (Valenciennes 1840) & $8(123-219)$ & & A & $\mathrm{D}$ & $\mathrm{ME}$ \\
\hline & & & Bagre bagre (Linnaeus 1758) & $1(372)$ & & $\mathrm{O}$ & $\mathrm{D}$ & $\mathrm{M}$ \\
\hline & & & Cathorops spixii (Agassiz 1829) & $144(60-288)$ & & A & $\mathrm{D}$ & $\mathrm{E}$ \\
\hline & & & Genidens barbus (Lacepede 1803) & $2(119-170)$ & $\mathrm{SE}$ & $\mathrm{O}$ & $\mathrm{D}$ & $\mathrm{ME}$ \\
\hline & & & Genidens genidens (Valenciennes 1840) & $36(65-225)$ & & $\mathrm{C}$ & $\mathrm{D}$ & $\mathrm{ME}$ \\
\hline & Callichthyidae & & Callichthys callichthys (Linnaeus 1758) & $2(80-85)$ & & $\mathrm{O}$ & $\mathrm{D}$ & $\mathrm{AD}$ \\
\hline Aulopiformes & Synodontidae & Synodontinae & Synodus foetens (Linnaeus 1766) & $1(38)$ & & $\mathrm{O}$ & $\mathrm{D}$ & M \\
\hline Batrachoidiformes & Batrachoididae & Porichthyinae & Porichthys porosissimus (Valenciennes 1837) & $1(288)$ & & $\mathrm{O}$ & $\mathrm{D}$ & $\mathrm{ME}$ \\
\hline Lophiiformes & Ogcocephalidae & & Ogcocephalus vespertilio (Linnaeus 1758) & $1(174)$ & & $\mathrm{O}$ & $\mathrm{D}$ & $\mathrm{M}$ \\
\hline Atheriniformes & Atherinopsidae & Atherinopsinae & Atherinella brasiliensis (Quoy e Gaimard 1824) & $65(30-139)$ & AS & A & $\mathrm{P}$ & $\mathrm{E}$ \\
\hline \multirow[t]{2}{*}{ Beloniformes } & Belonidae & & Strongylura timuсu (Walbaum 1792) & $11(355-406)$ & & $\mathrm{O}$ & $\mathrm{P}$ & $\mathrm{E}$ \\
\hline & & & Strongylura marina (Walbaum 1792) & $1(590)$ & & $\mathrm{O}$ & $\mathrm{P}$ & $\mathrm{E}$ \\
\hline Beryciformes & Holocentridae & Holocentrinae & Holocentrus adscensionis (Osbeck 1765) & $1(190)$ & & $\mathrm{O}$ & $\mathrm{D}$ & M \\
\hline Syngnathiformes & Syngnathidae & Syngnatinae & Syngnathus folletti Herald 1942 & $1(173)$ & & $\mathrm{O}$ & $\mathrm{D}$ & $\mathrm{ME}$ \\
\hline Scorpaeniformes & Triglidae & & Prionotus punctatus (Bloch 1793) & $15(60-147)$ & & A & $\mathrm{D}$ & $\mathrm{ME}$ \\
\hline \multirow[t]{26}{*}{ Perciformes } & Centropomidae & & Centropomus parallelus Poey 1860 & $3(100-221)$ & AS & A & $\mathrm{D}$ & $\mathrm{ME}$ \\
\hline & & & Centropomus undecimalis (Bloch 1792) & $1(340)$ & AS & $\mathrm{O}$ & $\mathrm{D}$ & $\mathrm{ME}$ \\
\hline & Serranidae & Serraninae & Diplectrum radiale (Quoy e Gaimard 1824) & $8(85-220)$ & & $\mathrm{O}$ & $\mathrm{D}$ & $\mathrm{ME}$ \\
\hline & & & Epinephelus marginatus (Lowe 1834) & $2(174-176)$ & $\mathrm{SE}$ & $\mathrm{O}$ & $\mathrm{D}$ & M \\
\hline & & & Mycteroperca acutirostris (Valenciennes 1828) & $1(322)$ & & $\mathrm{O}$ & $\mathrm{D}$ & M \\
\hline & & & Serranus flaviventris (Cuvier 1829) & $3(89-100)$ & & $\mathrm{O}$ & $\mathrm{D}$ & M \\
\hline & Pomatomidae & & Pomatomus saltatrix (Linnaeus 1766) & $1(78)$ & AS & $\mathrm{O}$ & $\mathrm{P}$ & M \\
\hline & Carangidae & & Caranx latus Agassiz 1831 & $11(140-220)$ & & A & $\mathrm{P}$ & ME \\
\hline & & & Chloroscombrus chrysurus (Linnaeus 1766) & $1(35)$ & & $\mathrm{O}$ & $\mathrm{P}$ & M \\
\hline & & & Hemicaranx amblyrhynchus (Cuvier 1833) & $1(287)$ & & $\mathrm{O}$ & $\mathrm{P}$ & M \\
\hline & & & Oligoplites palometa (Cuvier 1832) & $109(55-122)$ & & $\mathrm{O}$ & $\mathrm{P}$ & ME \\
\hline & & & Oligoplites saliens (Bloch 1793) & $1(313)$ & & $\mathrm{O}$ & $\mathrm{P}$ & $\mathrm{ME}$ \\
\hline & & & Selene setapinnis (Mitchill 1815) & $2(40-46)$ & & $\mathrm{O}$ & $\mathrm{P}$ & $\mathrm{ME}$ \\
\hline & & & Selene vomer (Linnaeus 1758) & $8(32-290)$ & & $\mathrm{O}$ & $\mathrm{P}$ & $\mathrm{ME}$ \\
\hline & & & Trachinotus carolinus (Linnaeus 1766) & $24(78-248)$ & & A & $\mathrm{P}$ & $\mathrm{ME}$ \\
\hline & & & Trachinotus falcatus (Linnaeus 1758) & $19(30-265)$ & & A & $\mathrm{P}$ & $\mathrm{ME}$ \\
\hline & Lobotidae & & Lobotes surinamensis (Bloch 1790) & $1(305)$ & & $\mathrm{O}$ & $\mathrm{D}$ & $\mathrm{ME}$ \\
\hline & Gerreidae & & Diapterus rhombeus (Cuvier 1829) & $60(138-190)$ & & A & $\mathrm{D}$ & $\mathrm{E}$ \\
\hline & & & Eucinostomus melanopterus (Bleeker 1863) & $3(82-106)$ & & $\mathrm{O}$ & $\mathrm{D}$ & ME \\
\hline & & & Eugerres brasilianus (Valenciennes 1830) & $1(250)$ & & $\mathrm{O}$ & $\mathrm{D}$ & $\mathrm{ME}$ \\
\hline & Haemulidae & & Anisotremus surinamensis (Bloch 1791) & $2(204-256)$ & & $\mathrm{O}$ & $\mathrm{D}$ & M \\
\hline & & & Anisotremus virginicus (Linnaeus1758) & $1(190)$ & & $\mathrm{O}$ & $\mathrm{D}$ & M \\
\hline & & & Conodon nobilis (Linnaeus 1758) & $1(150)$ & & $\mathrm{O}$ & $\mathrm{D}$ & $\mathrm{ME}$ \\
\hline & & & Genyatremus luteus (Bloch 1790) & $1(267)$ & & $\mathrm{O}$ & $\mathrm{D}$ & $\mathrm{ME}$ \\
\hline & & & Haemulon steindachneri (Jordan \& Gilbert 1882) & $9(98-260)$ & & A & $\mathrm{D}$ & $\mathrm{ME}$ \\
\hline & & & Orthopristis ruber (Cuvier 1830) & $1(197)$ & & $\mathrm{O}$ & $\mathrm{D}$ & M \\
\hline
\end{tabular}


Tabela 1. Continuação...

\begin{tabular}{|c|c|c|c|c|c|c|c|c|}
\hline Ordem & Família & Subfamília & Espécie & A & B & $\mathbf{C}$ & D & $\mathbf{E}$ \\
\hline & & & Pomadasys corvinaeformis (Steindacher 1868) & $16(30-160)$ & & $\mathrm{O}$ & $\mathrm{D}$ & $\mathrm{ME}$ \\
\hline & Sparidae & & Diplodus argenteus (Valenciennes 1830) & $1(110)$ & & $\mathrm{O}$ & $\mathrm{D}$ & $\mathrm{M}$ \\
\hline & Sciaenidae & & Bairdiella ronchus (Cuvier 1830) & $4(90-125)$ & & $\mathrm{O}$ & $\mathrm{D}$ & $\mathrm{ME}$ \\
\hline & & & Cynoscion acoupa (Lacepède 1801) & $1(450)$ & AS & $\mathrm{O}$ & $\mathrm{D}$ & $\mathrm{ME}$ \\
\hline & & & Cynoscion microlepidotus (Curvier 1830) & $1(311)$ & AS & $\mathrm{O}$ & $\mathrm{D}$ & $\mathrm{ME}$ \\
\hline & & & Isopisthus parvipinnis (Curvier 1830) & $3(168-188)$ & & $\mathrm{O}$ & $\mathrm{D}$ & $\mathrm{ME}$ \\
\hline & & & Larimus breviceps Cuvier 1830 & $1(170)$ & & $\mathrm{O}$ & $\mathrm{D}$ & $\mathrm{ME}$ \\
\hline & & & Menticirrhus americanus (Linnaeus 1758) & $7(118-314)$ & & A & $\mathrm{D}$ & $\mathrm{ME}$ \\
\hline & & & Micropogonias furnieri (Desmarest 1823) & $6(146-492)$ & $\mathrm{SE}$ & A & $\mathrm{D}$ & $\mathrm{ME}$ \\
\hline & & & Stellifer rastrifer (Jordan 1889) & $243(50-198)$ & & $\mathrm{C}$ & $\mathrm{D}$ & $\mathrm{ME}$ \\
\hline & & & Umbrina coroides Cuvier 1830 & $1(281)$ & & $\mathrm{O}$ & $\mathrm{D}$ & $\mathrm{ME}$ \\
\hline & Polynemidae & & Polydactylus virginicus (Linnaeus 1758) & $3(100-126)$ & & $\mathrm{O}$ & $\mathrm{D}$ & $\mathrm{ME}$ \\
\hline & Kyphosidae & Kyphosinae & Kyphosus sectatrix (Linnaeus 1758) & $2(240-290)$ & & $\mathrm{O}$ & $\mathrm{D}$ & M \\
\hline & Chaetodontidae & & Chaetodon striatus Linnaeus 1758 & $1(145)$ & & $\mathrm{O}$ & $\mathrm{D}$ & M \\
\hline & Mugilidae & & Mugil curema Valenciennes 1836 & $102(19-280)$ & & A & $\mathrm{P}$ & $\mathrm{ME}$ \\
\hline & & & Mugil liza Valenciennes 1836 & $3(301-385)$ & $\mathrm{SE}$ & $\mathrm{O}$ & $\mathrm{P}$ & $\mathrm{ME}$ \\
\hline & Pomacentridae & & Abudefduf saxatilis (Linnaeus 1758) & $2(135-180)$ & & $\mathrm{O}$ & $\mathrm{D}$ & M \\
\hline & Labrisomidae & & Labrisomus nuchippinis (Quoy e Gaimard 1824) & $2(180-185)$ & & $\mathrm{O}$ & $\mathrm{D}$ & M \\
\hline & Gobiidae & Gobionellinae & Bathygobius soporator (Valenciennes 1837) & $9(51-156)$ & & $\mathrm{O}$ & $\mathrm{D}$ & ME \\
\hline & Ephippidae & & Chaetodipterus faber (Broussonet 1782) & $11(40-160)$ & & $\mathrm{C}$ & $\mathrm{P}$ & M \\
\hline & Trichiuridae & & Trichiurus lepturus Linnaeus 1758 & $5(123-1150)$ & & A & $\mathrm{P}$ & $\mathrm{ME}$ \\
\hline & Scombridae & & Scomberomorus brasiliensis Collette et al. 1978 & $1(415)$ & & $\mathrm{O}$ & $\mathrm{P}$ & M \\
\hline & Stromateidae & & Peprilus paru Linnaeus 1758 & $2(188-265)$ & & $\mathrm{O}$ & $\mathrm{P}$ & $\mathrm{ME}$ \\
\hline \multirow[t]{9}{*}{ Pleuronectiformes } & Paralichthyidae & & Citharichthys spilopterus Gunter 1862 & $90(54-159)$ & & $\mathrm{C}$ & $\mathrm{D}$ & $\mathrm{E}$ \\
\hline & & & Etropus crossotus Jordan \& Gilbert 1882 & $14(65-122)$ & & A & $\mathrm{D}$ & $\mathrm{E}$ \\
\hline & Achiridae & & Achirus lineatus (Linnaeus 1758) & $57(56-132)$ & & $\mathrm{C}$ & $\mathrm{D}$ & $\mathrm{ME}$ \\
\hline & Cynoglossidae & Symphurinae & Symphurus tesselatus (Quoy e Gaimard 1824) & $6(81-170)$ & & A & $\mathrm{D}$ & $\mathrm{E}$ \\
\hline & Monacanthidae & & Aluterus monoceros (Linnaeus 1758) & $1(248)$ & & $\mathrm{O}$ & $\mathrm{P}$ & M \\
\hline & Tetraodontidae & & Lagocephalus laevigatus (Linnaeus 1766) & $13(52-110)$ & & $\mathrm{C}$ & $\mathrm{D}$ & $\mathrm{ME}$ \\
\hline & & & Sphoeroides greeleyi Gilbert 1900 & $3(93-195)$ & & $\mathrm{O}$ & $\mathrm{D}$ & $\mathrm{E}$ \\
\hline & & & Sphoeroides testudineus (Linnaeus 1758) & $3(85-120)$ & & A & $\mathrm{D}$ & $\mathrm{E}$ \\
\hline & Diodontidae & & Chilomycterus spinosus (Linnaeus 1758) & $2(129-165)$ & & $\mathrm{O}$ & $\mathrm{D}$ & $\mathrm{E}$ \\
\hline
\end{tabular}

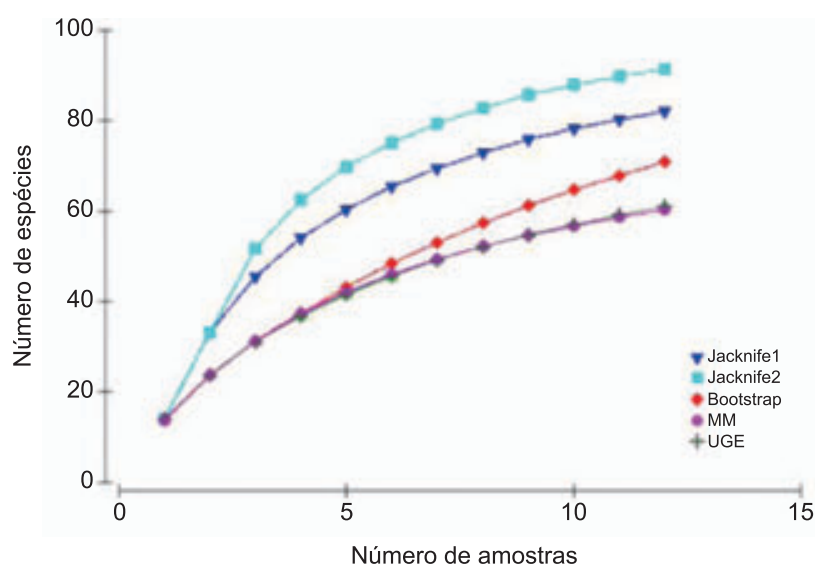

Figura 6. Curvas de suficiência da amostragem no trecho norte do Canal de Bertioga através dos estimadores não paramétricos de Jacknife 1, Jacknifre 2, Bootstrap, Michaelis Menton e UGE.

Figure 6. Sampling efficiency curves for the northern stretch of the Bertioga Channel using the non-parametric estimators Jackknife1, Jackknife2, Bootstrap, Michaelis Menton, and UGE.
Anchoviella lepidentostole $(\mathrm{n}=58)$, e Achirus lineatus $(\mathrm{n}=57)$ (Tabela 1). Das espécies encontradas, seis foram reconhecidas como constantes, 19 acessórias e 53 ocasionais (Tabela 1). Em relação aos seus hábitos, 40 espécies são marinho-estuarinas, 26 são marinhas, 11 estuarinas e uma de água doce, com 52 espécies demersais e 26 pelágicas (Tabela 1). Onze espécies são incluídas na lista de espécies ameaçadas de extinção do estado de São Paulo (São Paulo 2009), todas com importância para pesca comercial e/ou esportiva das regiões sudeste e sul do Brasil (Tabela 1).

A diversidade e abundância das espécies variaram nas diferentes áreas de coleta e estações do ano, como descrito a seguir.

\section{1. Áreas de estudo}

As três áreas de coleta apresentaram diferentes características físico-químicas e composição de espécies, porém não foi observada variação significativa de temperatura nas áreas amostradas (Tabela 2).

A área 1 (Figura 2b), localizada na porção mais interna do canal, apresentou os maiores valores médios anuais de salinidade (19,9\%), e os menores valores de $\mathrm{pH}(7,4)$ e oxigênio dissolvido $(67,2 \%)$, na superfície, e o maior valor médio de oxigênio dissolvido (62,3\%), 
Barbanti, B. et al.

Tabela 2. Parâmetros físico-químicos das localidades de coleta, média, valores mínimo e máximo na superfície e fundo.

Table 2. Physico-chemical parameters of collection localities, mean, minimum and maximum values from the surface and bottom.

\begin{tabular}{lccc}
\hline & Área 1 & Área 2 & Área 3 \\
\hline pH - superficie & $7,4(6,8-8,1)$ & $7,5(7,0-7,9)$ & $7,6(7,2-7,8)$ \\
pH - fundo & $7,7(7,0-8,1)$ & $7,7(7,4-8,0)$ & $7,7(7,6-8,1)$ \\
& & & \\
OD (\%) - superficie & $67,2(45,2-92,2)$ & $67,3(49,4-80,2)$ & $57,4(57,9-79,2)$ \\
OD (\%) - fundo & $62,2(45,2-75,4)$ & $55,3(38,2-75,0)$ & $17,3(13,8-20,9)$ \\
& & & \\
Salinidade (\%) - superfície & $19,8(14,6-27,07)$ & $16,5(12,4-21,9)$ & $25,7(19,9-30,8)$ \\
Salinidade $(\%)$ - fundo & $24(17,9-29,25)$ & $25,1(19,5-27,9)$ & \\
& & & $24,7(22,1-26,4)$ \\
Temperatura $\left({ }^{\circ} \mathbf{C}\right)$ - superficie & $25,9(22,3-27,5)$ & $24,8(22,1-26,4)$ & $24,2(21,6-26,7)$ \\
Temperatura $\left({ }^{\circ} \mathbf{C}\right)$ - fundo & $24,4(21,9-26,9)$ & $24,4(21,4-26,4)$ & \\
\hline
\end{tabular}

e os menores valores de $\mathrm{pH}(7,7)$ e salinidade $(24,0 \%)$, no fundo (Tabela 2). Na área, foram registrados valores intermediários dos índices de riqueza de Margalef (d) e de diversidade de ShannonWiener (H'), respectivamente $d=9,358$ e H'=3,526. As espécies mais abundantes foram Stellifer rastrifer $(\mathrm{n}=181)$, Cathorops spixii $(\mathrm{n}=$ 111) e Diapterus rhombeus ( $\mathrm{n}=60)$, com Centropomus undecimalis, Cynoscion acoupa, C. microlepidotus, Diapterus rhombeus, Genidens barbus, Oligoplites saliens, Porichthys porosissimus e Selene setapinnis, coletadas somente nesta área.

Aárea 2 (Figura 2c), localizada na confluência com o rio Itapanhaú, apresentou valores médios anuais mais baixos de salinidade (16,5\%), e oxigênio dissolvido (67,3\%), na superfície, e o valor médio mais alto de $\mathrm{pH}(7,7)$, no fundo (Tabela 2), com os menores índices de riqueza de espécies de Margalef (d) e de diversidade de ShannonWiener $\left(H^{\prime}\right)$, respectivamente $d=6,569$ e $H^{\prime}=3,045$. As espécies mais abundantes foram Stellifer rastrifer $(\mathrm{n}=39)$, Cathorops spixii $(\mathrm{n}=31)$ e Citharichthys spilopterus $(\mathrm{n}=26)$, sendo que Syngnathus folletti e Eugerres brasilianus foram encontradas somente nesta área.

A área 3 (Figura 2a), próxima à barra do canal, apresentou uma grande variação de salinidade conforme o regime de marés. Na área foram registrados os maiores valores médios anuais de $\mathrm{pH}(7,7)$ e oxigênio dissolvido $(69,4 \%)$, na superfície, com os maiores valores médios anuais de pH $(7,7)$ e salinidade (25,7\%), no fundo (Tabela 2). A área 1 apresentou os maiores índices de riqueza de Margalef (d) e de diversidade de Shannon-Wiener ( $\left.H^{\prime}\right)$, respectivamente $\mathrm{d}=$ 12,33 e H'= 3,892. As espécies mais abundantes foram Harengula clupeola $(\mathrm{n}=182)$, Oligoplites palometa $(\mathrm{n}=108)$ e Mugil curema $(\mathrm{n}$ =100), com outras espécies, típicas de costão rochoso, encontradas somente nesta área.

\section{Estações do ano}

Os índices de riqueza de Margalef (d) e de diversidade de ShannonWiener ( $H^{\prime}$ ), foram maiores no outono e inverno, respectivamente, d = 9,767 e 8,736, e H' = 3,584 e 3,434, com valores mais baixos na primavera e verão, respectivamente $d=7,889$ e 7,673, e 3,296 e 3,258. As espécies encontradas em todas estações do ano foram Achirus lineatus, Atherinella brasiliensis, Cathorops spixii, Chaetodipterus faber, Citharichthys spilopterus, Genidens genidens, Micropogonias furnieri e Stellifer rastrifer. No verão, as espécies mais abundantes foram Stellifer rastrifer $(\mathrm{n}=30)$, Cathorops spixii $(\mathrm{n}=16)$, Caranx latus $(\mathrm{n}=9)$, Citharichthys spilopterus $(\mathrm{n}=9)$ e Genidens genidens $(\mathrm{n}=9)$, no outono, Cathorops spixii $(\mathrm{n}=76)$, Mugil curema $(\mathrm{n}=72)$, Harengula clupeola $(\mathrm{n}=37)$ e Citharichthys spilopterus $(\mathrm{n}=23)$, no inverno, Harengula clupeola $(\mathrm{n}=144)$, Stellifer rastrifer $(\mathrm{n}=119)$, Oligoplites palometa $(\mathrm{n}=108)$, Atherinella brasiliensis $(\mathrm{n}=20)$,
Citharichthys spilopterus ( $\mathrm{n}=20)$, e na primavera, Stellifer rastrifer ( $\mathrm{n}=93)$, Diapterus rhombeus $(\mathrm{n}=60)$, Anchoviella lepidentostole $(\mathrm{n}=58)$ e Achirus lineatus $(\mathrm{n}=46)$.

\section{Discussão}

\section{A ictiofauna}

O trecho norte do Canal de Bertioga é caracterizado pela dominância de poucas espécies (as espécies constantes representaram $7,7 \%$ do total das espécies, Tabela 1), com um número moderado de espécies freqüentes (as espécies acessórias representaram 24,3\% do total de espécies, Tabela 1), e um grande número de espécies raras (as espécies ocasionais representaram 68\% do total das espécies, Tabela 1), condição comum em estudos da ictiofauna estuarina (Pinheiro 1999, Corrêa 2000, Santos et al. 2002, Vendel et al. 2003). Das 78 espécies encontradas no trecho norte do Canal de Bertioga, Stellifer rastrifer, Cathorops spixii e Citharichthys spilopterus destacaram-se pela abundância, sendo que a predominância numérica de Stellifer rastrifer, Cathorops spixii, Mugil curema, também foi observada no complexo estuarino de Santos-São Vicente (Vazzoler 1969, Paiva-Filho 1982, Paiva-Filho et al. 1987, Giannini \& PaivaFilho 1990, Fundação... 2006). Apenas Sardinella brasiliensis é restrita à Província Zoogeográfica Argentina, sendo que as demais espécies apresentam uma ampla distribuição.

O Canal de Bertioga pode ser considerado uma área de criadouro devido à predominância de exemplares juvenis de espécies marinhoestuarinas (Tabela 1), enquanto espécies tipicamente marinhas ocorreram principalmente na área 1 , onde os padrões hidrográficos representam um continuo do ambiente marinho adjacente. A baixa ocorrência de espécies residentes ou constantes pode ser justificada pelas dificuldades de adaptação a variação dos parâmetros ambientais num curto espaço de tempo (Day et al. 1989). Variação significativa dos índices de diversidade de Shannon-Wiener e riqueza de espécies de Margalef foi observada nas estações do ano, com maior diversidade e abundância no outono e inverno, final do período chuvoso e início do período de seca na região (Bernardes 2001). O tamanho médio dos exemplares permite interpretar que as espécies mais abundantes, exceção feita a Cathorops spixii, são representadas por indivíduos jovens (Tabela 1), que utilizam a região para alimentação, crescimento e proteção.

Das espécies capturadas no trecho norte do Canal de Bertioga, Centropomus parallelus, C. undecimalis, Anisotremus surinamensis, Chaetodipterus faber, Cynoscion acoupa, C. microlepdotus, Epinephelus marginatus, Eugerres braslianus, Genidens barbus, Isopisthus parvipinnis, Micropogonias furnieri, Mugil liza, 
Mycteroperca acutirostris, Pomatomus saltatrix, Sardinella brasiliensis, Scomberomorus brasiliensis, Trachinotus carolinus, T. falcatus, e Umbrina coroides são aquelas com maior interesse para pesca comercial que atua na plataforma continental adjacente, enquanto que Centropomus parallelus, C. undecimalis, Cynoscion acoupa, Trichiurus lepturus, Micropogonias furnieri e Epinephelus marginatus, são espécies alvo de pescadores esportivos que atuam no Canal de Bertioga. As espécies Bagre marinus (Mitchill 1815), Cynoscion jamaicensis (Vaillant \& Bocourt 1883), Cynoscion leiarchus (Cuvier 1830), Cynoscion virescens (Cuvier 1830), Hippocampus reidi Ginsburg 1933, Macrodon ancylodon (Bloch \& Schneider 1801), Pogonias cromis (Linnaeus 1766), e Umbrina canosai Berg 1895, incluídas na lista de espécies ameaçadas do estado de São Paulo (São Paulo 2009), não foram encontradas no trecho norte do Canal de Bertioga. Foram encontradas na área estudada, as seguintes espécies incluidas na lista de espécies ameaçadas do estado de São Paulo (São Paulo 2009): Atherinella brasiliensis, Centropomus parallelus, C. undecimalis, Cynoscion acoupa, C. microlepidotus, Genidens barbus, Epinephelus marginatus, Micropogonias furnieri, Mugil liza, Pomatomus saltatrix e Sardinella brasiliensis (Tabela 1).

A presença de Callichthys callichthys no canal de Bertioga, é interpretada como ocasional, após período de chuva intensa. Os exemplares observados possivelmente são originários do rio Itapanhaú.

\section{O Canal de Bertioga}

Estuários geralmente estão localizados em áreas sujeitas a grande pressão ambiental, decorrente da urbanização, industrialização e atividades portuárias, assim como do turismo, levando a uma crescente preocupação com a conservação destas áreas. O complexo estuarino da Baixada Santista, no qual o Canal de Bertioga está inserido, há muito tempo sofre forte pressão ambiental decorrente da dinâmica de ocupação humana e contaminação de seu complexo hídrico pelo complexo industrial de Cubatão e pelo complexo portuário de Santos, com áreas de manguezal altamente degradadas (Companhia...1991, Rodrigues et al 1995, Silva et al. 2008, CunhaLignon et al. 2009). Até bem pouco tempo, o difícil acesso à região de Bertioga minimizou o efeito de ações antrópicas sobre o complexo hídrico da região.

Nos dias atuais, o trecho sul do Canal de Bertioga está sujeito a diferentes fontes de pressão ambiental, enquanto no trecho norte, que não sofre influencia das águas provenientes do trecho sul (Bernardes 2001), encontramos áreas menos degradadas, mas que nas últimas décadas vêm sofrendo importantes alterações na paisagem natural decorrentes do aterro dos manguezais para construção de marinas e moradias, intenso tráfego de embarcações de médio a grande porte e atividade pesqueira de habitantes locais e turistas (Rodrigues et al. 1995). A construção da rodovia SP-55 e do oleoduto da Petrobrás permitiram o avanço da ocupação humana em áreas de floresta atlântica, restinga e manguezal na margem continental, enquanto que na margem insular (ilha de Santo Amaro), aproximadamente 107,3 ha de área de manguezal, o equivalente a 78,4\% da cobertura de manguezal original, foi desmatada e substituída por estruturas de apóio náutico (Cunha-Lignon et al. 2009). Apesar disso, o trecho norte do Canal de Bertioga é considerado importante como referência em estudos de contaminação do complexo hídrico da Baixada Santista (Lamparelli et al. 2007).

Ao contrario das demais áreas do complexo estuarino de SantosSão Vicente, a ictiofauna do trecho norte do Canal de Bertioga ainda não havia sido inventariada. Considerando que levantamentos faunísticos são a primeira etapa para o desenvolvimento de estudos ecológicos e biológicos em qualquer ambiente, a fim de estimar a potencialidade de exploração destes recursos, os resultados obtidos são de grande importância para elaboração de planos de gestão e conservação dos recursos naturais da região, assim como podem servir como fonte de consulta para identificação das espécies de peixes em futuros estudos de biologia e/ou ecologia na região.

\section{Chave de Identificação para as Espécies do Trecho norte do Canal de Bertioga}

1a. Nadadeira dorsal com raios moles, ou com um único espinho; nadadeira anal sem espinhos ... 2

1b. Nadadeira dorsal com mais de um espinho; nadadeira anal com espinhos ... 25

2a. Corpo marcadamente comprimido; olhos no mesmo lado da cabeça ... 3

2b. Corpo não marcadamente comprimido; olhos nunca no mesmo lado da cabeça ... 6

3a. Olhos geralmente do lado direito da cabeça; margem do pré-opérculo não visível, coberta por pele ... (Achiridae) ... Achirus lineatus (Figura 4q)

3b. Olhos geralmente do lado esquerdo da cabeça; margem do pré-opérculo visível, não coberta por pele... 4

4a. Nadadeiras dorsal e anal distintas da nadadeira caudal ... (Paralichthyidae) ... 5

4b. Nadadeiras dorsal e anal indistintas da nadadeira caudal ... (Cynoglossidae) ... Symphurus tesselatus (Figura 5r)

5a. Boca muito pequena, a extremidade posterior não alcançando a margem anterior do olho; rastros branquiais no primeiro arco branquial curtos e espinhosos ... Etropus crossotus (Figura 5p)

5b. Boca grande, a extremidade posterior alcançando a margem anterior do olho; rastros branquiais no primeiro arco branquial longos e não espinhosos ... Citharichthys spilopterus (Figura 5o)

6a. Corpo globoso e inflável, às vezes com espinhos; escamas verdadeiras ausentes ... (Tetraodontiformes) ... 7

6b. Corpo não globoso e não inflável, sempre sem espinhos; escamas verdadeiras presentes ou ausentes ... 11

7a. Corpo sem tubérculos e com espinhos ... (Diodontidae) ... Chilomycterus spinosus (Figura $5 \mathrm{w}$ )

7b. Corpo com tubérculos e sem espinhos ... 8

8a. Dentes fundidos em duas placas dentárias em cada maxila; espinho dorsal ausente ... (Tetraodontidae) ... 9

8b. Dentes não fundidos em cada maxila; espinho dorsal conspícuo e ereto presente ... (Monacanthidae) ... Aluterus monoceros (Figura 5s)

9a. Nadadeiras dorsal e anal com 13-14 raios cada uma... Lagocephalus laevigatus (Figura 5t)

9b. Nadadeiras dorsal e anal com 7-10 raios cada uma ... 10

10a. Presença de dois ou três flaps pequenos e achatados em cada lado do corpo; corpo com manchas grandes, escuras e arredondadas, contornadas por uma linha mais clara; região interorbital escura, com duas faixas transversais cor creme ... Sphoeroides testudineus (Figura 5v)

10b. Flaps ausentes em cada lado do corpo; corpo com manchas pequenas, pouco mais escuras do que o restante do corpo; região interorbital sem faixas transversais ... Sphoeroides greeleyi (Figura 5u)

11a. Escudos ósseos restritos à região ventral do corpo presentes; maxilas geralmente pequenas, com dentes não visíveis a olho nu, ou sem dentes; uma única nadadeira dorsal; nadadeira adiposa ausente ... (Clupeidae) ... 12

11b. Escudos ósseos na região ventral do corpo ausentes ou, se presentes, formando duas séries na face lateral do corpo; maxilas de tamanho variável, com dentes visíveis a olho nu; uma ou duas nadadeiras dorsais, nadadeira adiposa presente ... 13 
12a. Corpo comprimido; menos de 45 rastros no ramo inferior do primeiro arco branquial; nadadeira pélvica com oito raios ... Harengula clupeola (Figura 3b)

12b. Corpo roliço; mais de 45 rastros no ramo inferior do primeiro arco branquial; nadadeira pélvica com nove raios ... Sardinella brasiliensis (Figura 3c)

13a. Corpo sem escamas, mas às vezes com duas series laterais de placas ósseas; nadadeira dorsal e nadadeira peitoral com um espinho forte; dois a três pares de barbilhões carnosos em torno da boca sempre presentes ... 14

13b. Corpo com ou sem escamas, mas nunca com placas ósseas; nadadeira dorsal e nadadeira peitoral sem um espinho; barbilhões carnosos em torno da boca ausentes ... 19

14a. Corpo revestido por duas séries de placas ósseas; nadadeira adiposa ausente ... (Callichthyidae) ... Callichthys callichthys (Figura 3k)

14b. Corpo nu; nadadeira adiposa presente ... (Ariidae) ... 15

15a. Dois pares de barbilhões, o par maxilar em forma de fita e um par mental ... Bagre bagre (Figura 3g)

15b. Três pares de barbilhões, o par maxilar cilíndrico e dois pares mentais ... 16

16a. Placa nucal muito grande, arredondada ou quadriculada ... Aspistor luniscutis (Figura 3f)

16b. Placa nucal pequena, na forma de uma meia-lua ... 17

17a. Dentes molariformes grandes nas placas acessórias de dentes; nadadeira adiposa pequena, sua base cabendo duas vezes ou mais no comprimento da base da nadadeira anal ... Cathorops spixii (Figura 3h)

17b. Dentes cônicos pequenos nas placas acessórias de dentes; nadadeira adiposa de tamanho moderado, sua base cabendo 1,5 vezes no comprimento da base da nadadeira anal ... 18

18a. Placas acessórias de dentes sobre projeções carnosas móveis ... Genidens genidens (Figura 3j)

18b. Placas acessórias de dentes fixas no palato ... Genidens barbus (Figura 3i)

19a. Boca inferior; nadadeiras pélvicas em posição abdominal, com 7-14 raios; nadadeira adiposa ausente; 10-15 raios branquiostégios ... (Albulidae) ... Albula vulpes (Figura 3a)

19b. Boca geralmente terminal; nadadeiras pélvicas anteriores, com 6-7 raios; nadadeira adiposa presente ou ausente; menos de 10 raios branquiostégios... 20

20a. Nadadeira adiposa presente; extremidade posterior da maxila ultrapassando a linha vertical que passa pela borda posterior do olho; nadadeira dorsal posicionada atrás da nadadeira pélvica... (Synodontidae) ... Synodus foetens (Figura 3L)

20b. Nadadeira adiposa ausente; extremidade posterior da maxila geralmente não alcançando a linha vertical que passa pela borda posterior do olho; nadadeira dorsal posicionada à frente da nadadeira pélvica... 21

21a. Focinho longo, com maxilas fixas, estendidas para frente; nadadeiras pélvicas abdominais; linha lateral próxima à margem ventral do corpo ... (Belonidae) ... 22

21b. Focinho curto, com maxilas móveis, não estendidas para frente; nadadeiras pélvicas não abdominais; linha lateral distante da margem ventral do corpo ... 23

22a. Escamas pequenas, em 215-304 séries transversais, entre a borda posterior do olho e a origem da nadadeira dorsal; sem uma faixa escura na região mediana do tronco ... Strongylura marina (Figura 3p)

22b. Escamas grandes, em 120-185 séries transversais, entre a borda posterior do olho e a origem da nadadeira dorsal; com uma faixa escura na região mediana do tronco ... Strongylura timucu (Figura 3q) 23a. Focinho longo e tubular; dentes ausentes; corpo revestido por anéis ósseos; nadadeiras pélvicas ausentes ... (Syngnathidae) ... Syngnathus folletti (Figura 3s)

23b. Focinho obtuso e não tubular; dentes presentes; corpo não revestido por anéis ósseos; nadadeiras pélvicas presentes ... (Engraulidae) ... 24

24a. Dentes da mandíbula grandes e espaçados ... Lycengraulis grossidens (Figura 3d)

24b. Dentes da mandíbula pequenos e não espaçados ... Anchoviella lepidentostole (Figura 3e)

25a. Nadadeiras pélvicas inseridas à frente da nadadeira dorsal; primeira nadadeira dorsal com três a quatro espinhos ... 26

25b. Nadadeiras pélvicas inseridas atrás da nadadeira dorsal; primeira nadadeira dorsal com quatro ou mais espinhos ... 27

26a. Pele com dentículos grossos e cônicos; nadadeira peitoral modificadas para apoiar no substrato; apêndice carnoso acima da cabeça presente; linha lateral ausente ... (Ogcocephalidae) ... Ogcocephalus vespertilio (Figura 3n)

26b. Pele sem dentículos; nadadeira peitoral não modificadas para apoiar no substrato; apêndice carnoso acima da cabeça ausente; linha lateral presente ... (Batrachoididae) ... Porichthys porosissimus (Figura 3m)

27a. Nadadeiras dorsais separadas por uma distância maior que o comprimento da base da primeira nadadeira dorsal ... 28

27b. Nadadeiras dorsais separadas por uma distância menor que o comprimento da base da primeira nadadeira dorsal, às vezes constituindo uma única nadadeira ... 30

28a. Boca não protrátil; olhos recobertos por pálpebras adiposas; base da nadadeira anal aproximadamente do mesmo comprimento da base da segunda nadadeira dorsal ... (Mugilidae) ... 29

28b. Boca protrátil; olhos não cobertos por pálpebras adiposas; base da nadadeira anal muito maior do que a base da segunda nadadeira dorsal ... (Atherinopsidae) ... Atherinella brasiliensis (Figura 3o)

29a. Segunda nadadeira dorsal e nadadeira anal cobertas por escamas; geralmente com 38-39 escamas na série longitudinal; corpo sem faixas longitudinais escuras ... Mugil curema (Figura 5f)

29b. Segunda nadadeira dorsal e nadadeira anal não cobertas por escamas; geralmente com 30-34 escamas na série longitudinal; corpo com faixas longitudinais escuras ... Mugil liza (Figura 5g)

30a. Pré-opérculo e opérculo com margens serrilhadas e um espinho alongado; sete raios na nadadeira pélvica ... (Holocentridae) ... Holocentrus adscensionis (Figura 3r)

30b. Pré-opérculo e opérculo com margens não serrilhadas ou, se serrilhadas, sem um espinho alongado; seis raios na nadadeira pélvica ... 31

31a. Raios inferiores da nadadeira peitoral destacados ... 32

31b. Raios inferiores da nadadeira peitoral unidos... 33

32a. Cabeça grande, coberta de espinhos e com duas projeções arredondadas pequenas na margem anterior; raios da nadadeira peitoral espessos, formando apêndices para caminhar no substrato ... (Triglidae) ... Prionotus punctatus (Figura 3t)

32b. Cabeça pequena sem espinhos e/ou projeções na margem anterior; raios das nadadeiras peitorais delgados e filamentosos, não formando apêndices para caminhar no substrato ... (Polynemidae) ... Polydactylus virginicus (Figura 5c)

33a. Nadadeira anal com dois espinhos ... (Carangidae) ... 34

33b. Nadadeira anal sem espinhos ... 42

34a. Escamas na porção posterior da linha lateral modificadas em escudos ... 35

34b. Escamas na porção posterior da linha lateral não modificados em escudos ... 39 
35a. Corpo muito comprimido, perfil ventral muito mais convexo do que o perfil dorsal; nadadeira peitoral ultrapassando a linha vertical que passa pela base da nadadeira pélvica; cinco a 15 escudos diminutos na linha lateral ... 36

35b. Corpo pouco comprimido, perfil dorsal e ventral igualmente convexos; nadadeira peitoral não ultrapassando a linha vertical que passa pela base da nadadeira pélvica; mais de 23 escudos grandes da linha lateral ... 38

36a. Nadadeira anal com 25 a 28 raios; perfil ventral do corpo mais convexo do que o perfil dorsal; mancha escura no pedúnculo caudal presente ... Chloroscombrus chrysurus (Figura 4b)

36b. Nadadeira anal com 16 a 20 raios; perfil dorsal e ventral do corpo igualmente convexo; mancha escura no pedúnculo caudal ausente ... 37

37a. Perfil da cabeça aproximadamente vertical na região dos olhos; 31 a 35 rastros no primeiro arco branquial; raios anteriores das nadadeiras dorsal e anal prolongados ... Selene vomer (Figura 4g)

37b. Perfil da cabeça côncavo na região dos olhos; 34 a 44 rastros no primeiro arco branquial; raios anteriores das nadadeiras dorsal e anal não prolongados ... Selene setapinnis (Figura 4f)

38a. Maxila superior com uma única série de dentes; quilhas no pedúnculo caudal ausentes; porção anterior da linha lateral sinuosa, com menos da metade do comprimento da porção reta ... Hemicaranx amblyrhynchos (Figura 4c)

38b. Maxila superior com várias séries de dentes; duas quilhas em cada lado do pedúnculo caudal; porção anterior da linha lateral sinuosa, com mais da metade do comprimento da porção posterior reta ... Caranx latus (Figura 4a)

39a. Boca grande, o comprimento da maxila superior contido menos de duas vezes no comprimento da cabeça; raios posteriores da nadadeira dorsal e da nadadeira anal destacados ... 40

39b. Boca pequena, o comprimento da maxila superior contido mais de duas vezes no comprimento da cabeça; raios posteriores da nadadeira dorsal e da nadadeira anal unidos... 41

40a. Maxila superior com uma única série de dentes; perfil ventral da maxila inferior muito saliente; 17 a 20 rastros branquiais no ramo inferior do primeiro arco branquial, excluindo os rudimentos ... Oligoplites saliens (Figura 4e)

40b. Maxila superior com duas séries de dentes; perfil ventral da maxila inferior retilíneo; 11 a 15 rastros branquiais no ramo inferior do primeiro arco branquial, excluindo os rudimentos ... Oligoplites palometa (Figura 4d)

41a. Olho muito menor do que o comprimento do focinho; 17 a 21 raios na nadadeira dorsal; 16 a 19 raios prolongados na nadadeira anal ... Trachinotus falcatus (Figura 4i)

41b. Olho pouco menor do que o comprimento do focinho; 22 a 27 raios na nadadeira dorsal; 20 a 24 raios pouco prolongados na nadadeira anal ... Trachinotus carolinus (Figura 4h)

42a. Últimos raios da segunda nadadeira dorsal e da nadadeira anal destacados e ramificados; pedúnculo caudal com dois a três quilhas de cada lado ... (Scombridae) ... Scomberomorus brasiliensis (Figura 5m)

42b. Últimos raios da segunda nadadeira dorsal e da nadadeira anal não destacados e ramificados; pedúnculo caudal geralmente sem quilhas ... 43

43a. Corpo em forma de fita; nadadeira pélvica ausentes; dentes em forma de punhal ... (Trichiuridae) ... Trichiurus lepturus (Figura 5L)

43b. Corpo nunca em forma de fita; nadadeira pélvica presentes; dentes nunca em forma de punhal ... 44

44a. Boca protrátil, formando um tubo; segunda nadadeira dorsal com uma bainha de escamas na base ... Gerreidae ... 45 44b. Boca geralmente não protrátil, nunca formando um tubo; segunda nadadeira dorsal geralmente sem uma bainha de escamas na base ... 47

45a. Margem do pré-opérculo serrilhada; primeira nadadeira dorsal sem uma mancha escura ... 46

45b. Margem do pré-opérculo lisa; primeira nadadeira dorsal com uma mancha escura ... Eucinostomus melanopterus (Figura 4L)

46a. Região pré-orbital serrilhada; corpo com várias faixas longitudinais escuras; nadadeira anal geralmente com três espinhos e sete raios; ramo inferior do primeiro arco branquial com 10 a 12 rastros... Eugerres brasilianus (Figura 4m)

46b. Região pré-orbital não serrilhada; corpo sem faixas longitudinais escura; nadadeira anal geralmente com dois espinhos e nove raios; ramo inferior do primeiro arco branquial com 16 a 18 rastros ... Diapterus rhombeus (Figura 4k)

47a. Linha lateral alcançando a extremidade posterior da nadadeira caudal ... 48

47b. Linha lateral alcançando a base da nadadeira caudal ... 58

48a. Mento com quatro ou cinco poros sensoriais; nadadeira dorsal com 18 a 40 raios ... (Sciaenidae) ... 49

48b. Mento sem poros sensoriais; nadadeira dorsal com oito a 13 raios ... (Centropomidae) ... 57

49a. Mandíbula com barbilhões ... 50

49b. Mandíbula sem barbilhões ... 52

50a. Mandíbula com um único barbilhão rígido; corpo com grandes manchas escuras oblíquas e faixas transversais ... 51

50b. Mandíbula com várias séries de barbilhões filamentosos; corpo com linhas escuras estreitas e onduladas ... Micropogonias furnieri (Figura 4ab)

51a. Corpo alongado, perfil ventral retilíneo; 22 a 26 raios na segunda nadadeira dorsal; corpo com manchas marrom-escuras oblíquas e sem faixas transversais ... Menticirrhus americanus (Figura 4aa)

51b. Corpo alto, perfil ventral convexo; 26 a 30 raios na segunda nadadeira dorsal; corpo com faixas escuras estreitas acompanhando as séries de escamas e com cerca de nove faixas transversais ... Umbrina coroides (Figura 5b)

52a. Boca muito inclinada, a mandíbula fortemente convexa; 28 a 36 rastros branquiais longos, maiores que o diâmetro do olho ... Larimus breviceps (Figura 4z)

52b. Boca pouco inclinada, a mandíbula pouco convexa; menos de 25 rastros branquiais curtos, menores que o diâmetro do olho ... 53

53a. Nadadeiras dorsais separadas; nadadeira anal com 18 a 20 raios ... Isopisthus parvipinnis (Figura 4y)

53b. Nadadeiras dorsais unidas, ainda que com um entalhe entre elas; nadadeira anal com menos de 20 raios ... 54

54a. Maxilas com uma única série de dentes grandes, alguns dos quais caniniformes ... 55

54b. Maxilas com várias séries de dentes pequenos e cônicos ... 56

55a. Escamas ctenoides; base da segunda nadadeira dorsal com uma bainha estreita de escamas; 17 a 22 raios na segunda nadadeira dorsal; 100 a 115 séries transversais de escamas acima da linha lateral ... Cynoscion acoupa (Figura 4w)

55b. Escamas ciclóides; base da segunda nadadeira dorsal com uma bainha ampla de escamas; 22 a 25 raios na segunda nadadeira dorsal; 130 a 150 séries transversais de escamas acima da linha lateral ... Cynoscion microlepidotus (Figura 4x)

56a. Cabeça de consistência esponjosa, deformável ao toque, ossos com cavidades grandes; região infraorbital larga, quase tão larga quanto diâmetro do olho ... Stellifer rastrifer (Figura 5a)

56b. Cabeça de consistência não esponjosa, não deformável ao toque, ossos sem cavidades; região infraorbital estreita, muito menor do que o diâmetro do olho ... Bairdiella ronchus (Figura 4v) 
57a. Corpo alto, altura do corpo $67 \%$ a $81 \%$ do comprimento da cabeça; ramo inferior do primeiro arco branquial com 10 a 12 rastros; linha lateral com 65-70 escamas ... Centropomus parallelus (Figura 3u)

57b. Corpo alongado, altura do corpo 59\% a 64\% do comprimento da cabeça; ramo inferior do primeiro arco branquial com sete a oito rastros; linha lateral com 70-74 escamas ... Centropomus undecimalis (Figura 3v)

58a. Opérculo com um a três espinhos ... (Serranidae) ... 59

58b. Opérculo sem espinhos ... 62

59a. Pré-opérculo serrilhado e com uma projeção saliente ... Diplectrum radiale (Figura 3x)

59b. Pré-opérculo não serrilhado e sem uma projeção saliente ... 60

60a. Dentes nas maxilas não depressíveis; ventre com uma mancha esbranquiçada e duas manchas escuras no pedúnculo caudal ... Serranus flaviventris (Figura 3z)

60b. Dentes nas maxilas depressíveis; ventre e pedúnculo caudal sem manchas esbranquiçadas ou escuras ... 61

61a. Nadadeira anal com 10 a 12 raios; com uma faixa escura entre a maxila superior e o pré-opérculo; 48 a 55 rastros branquiais no primeiro arco branquial ... Mycteroperca acutirostris (Figura 3w)

61b. Nadadeira anal com oito a nove raios; sem uma faixa escura entre a maxila superior e o pré-opérculo; 22 a 35 rastros branquiais no primeiro arco branquial ... Epinephelus marginatus (Figura 3y)

62a. Nadadeira pélvica modificada em um disco adesivo; linha lateral sempre ausente; primeiros raios da nadadeira peitoral destacados formando filamentos ... (Gobiidae) ... Bathygobius soporator (Figura 5j)

62b. Nadadeira pélvica não modifica em disco adesivo; linha lateral geralmente presente; primeiros raios da nadadeira peitoral não destacados e não formando filamentos ... 63

63a. Corpo alto, em forma de disco, com raios das nadadeiras dorsal e anal prolongados; três ou quatro espinhos na nadadeira dorsal, muito pequenos, às vezes sob a pele ... (Stromateidae) ... Peprilus paru (Figura 5n)

63b. Corpo relativamente baixo, se na forma de disco, com raios das nadadeiras dorsal e anal não prolongados; seis ou mais espinhos na nadadeira dorsal, muito evidentes ... 64

64a. Cirros na cabeça presentes; número de espinhos na primeira nadadeira dorsal maior do que o número de raios na segunda nadadeira dorsal ... (Labrisomidae) ... Labrisomus nuchipinnis (Figura 5i)

64b. Cirros na cabeça ausentes; número de espinhos na primeira dorsal geralmente menor do que o número de raios na segunda nadadeira dorsal ... 65

65a. Escamas presentes entre a boca e os olhos; mento com um par de poros; boca com lábios espessos; quatro a cinco séries de dentes ... (Haemulidae) ... 66

65b. Escamas ausentes entre a boca e os olhos; mento sem poros; boca com lábios delgados; três ou menos series de dentes ... 72

66a. Pré-opérculo com espinhos grandes; 11 espinhos na nadadeira dorsal; corpo com oito faixas transversais escuras ... Conodon nobilis (Figura 4p)

66b. Pré-opérculo sem espinhos; 14-13 espinhos na nadadeira dorsal; corpo sem faixas transversais escuras ... 67

67a. Nadadeira dorsal e nadadeira anal com escamas em quase toda extensão; boca avermelhada em exemplares frescos; mancha negra entre o pré-opérculo e o opérculo presente ... Haemulon stendachneri (Figura 4r)

67b. Nadadeira dorsal e nadadeira anal com escamas apenas na base e parte das membranas interadiais; boca não avermelhada em exemplares frescos; mancha negra entre o pré-opérculo e o opérculo ausente ... 68 68a. Mento com dois pares de poros muito pequenos; nadadeira dorsal com 13 espinhos e 12 raios; perfil da cabeça acima dos olhos côncavo ... Genyatremus luteus (Figura 4q)

68b. Mento com um par de poros pequenos, precedido por um poro mediano grande; nadadeira dorsal com 12 espinhos e 14-13 raios; perfil da cabeça acima dos olhos convexo ... 69

69a. Altura do corpo entre $40 \%$ a 50\% do comprimento padrão; lábios espessos ... 70

69b. Altura do corpo inferior a $40 \%$ do comprimento padrão; lábios delgados ... 71

70a. Corpo amarelado, com faixas longitudinais; com uma faixa escura vertical passando pela borda posterior do opérculo e outra faixa escura oblíqua passando pelo olho ... Anisotremus virginicus (Figura 4o)

70b. Corpo acinzentado, sem faixas longitudinais; com uma área escura entre a nadadeira peitoral e o ventre ... Anisotremus surinamensis (Figura 4n)

71a. Nadadeira anal com nove a 11 raios; corpo com manchas pequenas, arredondadas e escuras, formando linhas oblíquas ... Orthopristis ruber (Figura 4s)

71b. Nadadeira anal com seis a sete raios; corpo com faixas escuras longitudinais acompanhando as séries de escamas ... Pomadasys corvinaeformis (Figura 4t)

72a. Uma única série de dentes incisivos nas maxilas ... 73

72b. Uma a três séries de dentes nas maxilas, quando com uma única série, nunca com dentes incisivos ... 74

73a. Boca grande, ultrapassando margem anterior da órbita; dentes grandes, visíveis a olho nu; linha lateral alcançando o pedúnculo caudal; corpo prateado, com uma mancha escura no pedúnculo caudal ... (Sparidae) ... Diplodus argenteus (Figura 4u)

73b. Boca pequena, não alcançando a margem anterior da órbita; dentes pequenos, não visíveis a olho nu; linha lateral não alcançando o pedúnculo caudal; corpo com faixas transversais escuras, sem uma mancha no pedúnculo caudal ... (Pomacentridae) ... Abudefduf saxatilis (Figura 5 h)

74a. Uma única série de dentes curvos nas maxilas; extremidade anterior da maxila muito à frente da extremidade anterior da mandíbula; cabeça com uma saliência sutil acima dos olhos ... Kyphosus saltatrix (Figura 5d)

74b. Mais de uma série de dentes nas maxilas, quando somente uma única série, nunca com dentes curvos; extremidade anterior da maxila e da mandíbula aproximadamente no mesmo nível; cabeça sem saliência acima dos olhos ... 75

75a. Corpo muito alto e comprimido, em forma de disco; dentes em forma de cerdas ... 76

75b. Corpo baixo e moderadamente comprimido, nunca em forma de disco; dentes nunca em forma de cerdas ... 77

76a. Nadadeiras dorsais contínuas; raios da segunda nadadeira dorsal e da nadadeira anal não prolongados; corpo com faixas transversais escuras conspícuas presentes ... (Chaetodontidae) ... Chaetodon striatus (Figura 5e)

76b. Nadadeiras dorsais separadas por um entalhe; raios da segunda nadadeira dorsal e da nadadeira anal prolongados; corpo com faixas transversais escuras inconspícuas ou ausentes ... (Ephippidae) ... Chaetodipterus faber (Figura 5k)

77a. Focinho curto, pouco maior do que o comprimento do olho; maxilas com várias séries de dentes pequenos e cônicos; segunda nadadeira dorsal e nadadeira anal prolongadas até a base da nadadeira caudal; espinhos da nadadeira dorsal pouco mais curtos do que os raios; corpo escuro ... (Lobotidae) ... Lobotes surinamensis (Figura 4j)

77b. Focinho longo, muito maior do que o comprimento do olho; maxilas com uma única série de dentes grandes e comprimidos; segunda nadadeira dorsal e nadadeira anal não prolongadas até a base 
da nadadeira caudal; espinhos da nadadeira dorsal muito mais curtos do que os raios; corpo azulado ou esverdeado na metade superior, prateado na metade inferior ... (Pomatomidae) ... Pomatomus saltatrix (Figura 3aa)

\section{Agradecimentos}

Aos pescadores profissionais da Colônia de Pescadores Z-23, em Bertioga, pelas informações e auxílio nas coletas. Agradecemos a Dra. Bianca Bentes (UFPA) pelo auxílio na análise ecológica-estatistica, a Profa Dra Maria Santina de Castro Morini (UMC) pela leitura do texto final, a UMC (Universidade de Mogi das Cruzes) pelo apoio institucional as atividades de pesquisas (APM e BB), e ao CNPq pela bolsa de pesquisa de APM (processo 152782/2007-9). O primeiro autor agradece ao IBAMA pela licença de coleta (número: 22841-1).

\section{Referências Bibliográficas}

BERNARDES, M.E.C. 2001. Circulação Estacionária e Estratificação de Sal em Canais Estuarinos Parcialmente Misturados: Simulação com Modelos Analíticos. Dissertação de Mestrado, Instituto Oceanográfico de São Paulo.

CARVAlHO-FILHO, A. 1999. Peixes: Costa Brasileira. Ed. Melro Ltda, São Paulo.

CASTRO, R.M.C. \& MENEZES, N.A. 1998. Estudo diagnostico da diversidade de peixes do estado de São Paulo. In: Biodiversidade do Estado de São Paulo, Brasil: Síntese do conhecimento ao final do século XX, 6: vertebrados (R.M.C. Castro, ed.). WinnerGraph, São Paulo, p.1-13.

COLWELL, R.K. \& CODDINGTON, J. A. 1994. Estimating terrestrial biodiversity through extrapolation. Philos. Trans. R. Soc. London, Ser. B. 345:101-118. http://dx.doi.org/10.1098/rstb.1994.0091

COLWELL, R.K., MAO, C.X. \& CHANG, J. 2004. Interpolating, extrapolating, and comparing incidence-based species accumulation curves. BMC Ecol. 85:2717-2727.

COMPANHIA DE TECNOLOGIA DE SANEAMENTO AMBIENTAL - CETESB. 1991. Avaliação do Estado da Degradação dos Ecossistemas da Baixada Santista - SP, Relatório Técnico, 45p.

CORRÊA, M.F.M. 2000. Ictiofauna Demersal da Baía de Guaraqueçaba (Paraná, Brasil). Composição, Estrutura, Distribuição Espacial, Variabilidade Temporal e Importância como Recurso. Tese de Doutorado em Zoologia, Universidade Federal do Paraná, Curitiba.

CUNHA-LIGNON, M., MENGHINI, R.P., SANTOS, L.C.M., NIEMEYERDINÓLA, C. \& SCHAEFFER-NOVELLI, Y. 2009. Estudos de Caso nos Manguezais do Estado de São Paulo (Brasil): Aplicação de Ferramentas com Diferentes Escalas Espaço-Temporais. Rev. Gestão Costeira Integrada 9(1):79-91. http://dx.doi.org/10.5894/rgci125

DAJOZ, R. 1973. Ecologia Geral. Vozes Ltda, Editora da Universidade de São Paulo, 472p.

DAY, J.W., HALL, C.A.S., KEMP, W.M. \& YANEZ-ARANCIBIA, A. 1989. Estuarine ecology. New York, John Wiley and Sons.

ESCHMEYER, W.N. 2011. Catalog of Fishes on-line. California Academy of Sciences. http://research.calacademy.org/research/ichthyology/catalog/ fishcatmain.asp (último acesso em 10/12/2011).

FAGUNDES, L., TOMÁS, A.R.G., CASARINI, L.M., BUENO, E.F., LOPES, G.M., MACHADO, D.A.L., BRAGA, R.A.R.C.A., CAMARGO, F.B.C. \& OBERG, I.M.F. 2007. A Pesca de Arrasto de Praia na Ilha de São Vicente, São Paulo, Brasil. Bol. Inst. Pesca, 29:1-43.

FOOD AND AGRICULTURE ORGANIZATION OF THE UNITED NATIONS - FAO. 2003. The Living Marine Resources of the Western Central Atlantic. Bone Fishes part 1, Rome, v. 2.

FIGUEIREDO, J.L. 1981. Estudo das Distribuições Endêmicas de Peixes da Província Zoogeográfica Marinha Argentina. Tese de doutorado. Universidade de São Paulo, Instituto de Biociências.

FIGUEIREDO, J.L. \& MENEZES, N.A. 1978. Manual de Peixes Marinhos do Sudeste do Brasil. II. Teleostei (1). Museu de Zoologia da Universidade de São Paulo, São Paulo.
FIGUEIREDO, J.L. \& MENEZES, N.A. 1980. Manual de Peixes Marinhos do Sudeste do Brasil. III. Teleostei (2). Museu de Zoologia da Universidade de São Paulo, São Paulo.

FIGUEIREDO, J.L. \& MENEZES, N.A. 2000. Manual de Peixes Marinhos do Sudeste do Brasil. VI. Teleostei (5). Museu de Zoologia da Universidade de São Paulo, São Paulo.

FUNDAÇÃO RICARDO FRANCO. 2006. EIA-RIMA para o Licenciamento da Dragagem de Aprofundamento do Canal de Santos.

F U N D A Ç Ã O D E E T T D O S E P E S Q U IS A S AQUÁTICAS - FUNDESPA. 1991. Condições Oceanográficas no Canal da Bertioga. Relatório Final, 251p.

GIANNINI, R. \& PAlVA-FILHO, A.M. 1990. Os Sciaenidae (Teleostei: Perciformes) da Baía de Santos (SP), Brasil. Bol. Inst. Oceanogr. 38(1):69-86. http://dx.doi.org/10.1590/S037355241990000100008

GIANNINI, R. \& PAIVA-FILHO, A.M., 1992. Aspectos da Bioecologia de Menticirrhus americanus (Teleostei, Sciaenidae) na Baía de Santos, SP, Brasil. Bol. Inst. Pesca 19:1-15.

GIANNINI, R. \& PAIVA-FILHO, A.M. 1995. Análise Comparativa da Ictiofauna da Zona de Arrebentação de Praias Arenosas do Estado de São Paulo, Brasil. Bol. Inst. Oceanogr. 43(2):141-152.

GOITEIN, R. 1984. Aspectos da Alimentação dos Clupeidae Harengula clupeola (Cuvier, 1829) e Opisthonema oglinum (Lesueur, 1818), e dos Engraulidae Anchoviella lepidentostole (Fowler,1911) e Cetengraulis edentulus (Cuvier, 1828) no Estuário de São Vicente, São Vicente, SP. Tese de Doutorado, Universidade de São Paulo.

GOITEIN, R. \& MESQUITA FILHO, J.D. 1985. Aspectos da Alimentação dos Cupeiformes Harengula clupeola (Cuvier, 1829) e Ophisthonema oglinum (Lesueur, 1818) (Clupeidae) e Anchoviella lepidentostole (Fowler, 1911) e Cetengraulis edentulus (Cuvier, 1828) (Engraulidae) no Estuário de São Vicente. In XII Congresso Brasileiro de Zoologia, Campinas. p. 180-181.

LAMPARELLI, M., QUINÁGLIA, G.A., OLIVEIRA, E., TOMINAGA, M.Y., SANTOS, P.E., RECH, C.M., UMBUZEIRO, G.A., SATO, M.I.Z. \& BEVILÁCQUA, J.E. 2007. Bertioga as a Possible Reference Region for Studies in the Baixada Santista for Carcinogenic Metals, Polycyclic Aromatic Hydrocarbons and Mutagenicity. In VIII Congresso Brasileiro de Mutagênese, Carciogênese e Teratogênese Ambiental. Angra dos Reis. Rev. Bras. Toxicologia 20:1-1.

LUEDERWALDT, H. 1919. Os Manguezais de Santos. Revista do Museu Paulista. Editora Diário Oficial, Tomo XI.

MARCENIUK, A.P. 2005. Chave de Identificação das Espécies de Bagres Marinhos (Siluriformes, Ariidae) da Costa Brasileira. Bol. Inst. Pesca, 31(2):89-101.

MENEZES, N.A. \& FIGUEIREDO, J.L. 1980. Manual de peixes marinhos do sudeste do Brasil, IV. Teleostei (3). Universidade de São Paulo, Museu de Zoologia, São Paulo.

MENEZES, N.A. \& FIGUEIREDO, J.L. 1985. Manual de Peixes Marinhos do Sudeste do Brasil. V. Teleostei (4). Universidade de São Paulo, Museu de Zoologia, São Paulo.

MENEZES, N.A., BUCKUP, P.A., FIGUEIREDO, J.L. \& MOURA, R.L. 2003. Catálogo das espécies de peixes marinhos do Brasil. Universidade de São Paulo, Museu de Zoologia, São Paulo.

MIRANDA, L.B., CASTRO, B.M. \& KJERFVE, B. 1998. Circulation and Mixing Due to Tidal Forcing in the Bertioga Channel, São Paulo, Brazil. Estuaries, 21(2):204-214. http://dx.doi.org/10.2307/1352469

PAIVA-FILHO, A.M. 1982. Estudo sobre a Ictiofauna do Canal dos Barreiros, Estuário de São Vicente, SP. Tese de Livre-Docência, Universidade de São Paulo.

PAIVA-FILHO, A.M., TEIXEIRA, M.D.L.Z. \& KIHARA, P.K. 1986. Contribuição ao Conhecimento da Biologia da Manjuba, Anchoviella lepidentostole (Fowler, 1911), no Estuário de São Vicente, SP. (Osteichthyes, Engraulidae). Bol. Inst. Oceanogr. 34.

PAIVA-FILHO, A.M. \& TOSCANO, A.P. 1987. Estudo Comparativo da Variação da Ictiofauna na Zona Entre-marés do Mar Casado-Guarujá e Mar Pequeno-São Vicente, SP. Bol. Inst. Oceanogr. 35(2):153-165.

PAIVA-FILHO, A.M., GIANNINI, R., RIBEIRO NETO, F.B. \& SCHMIEGELOW, J.M.M. 1987. Ictiofauna do Complexo Baia Estuário de Santos e São Vicente, SP, Brasil. Bol. Inst. Oceanogr. 17:1-10. 
PAIVA-FILHO, A.M \& GIANNINI, R. 1990. Contribuição ao conhecimento da biologia do peixe-rei, Xenomelaniris brasiliensis (Quoy \& Gaimard, 1824) (Atherinidae), no Complexo baía-estuário de Santos e São Vicente, Brasil. Bol. Inst. Oceanogr. 38(1):1-9.

PALMER, M.W. 1990. The estimation of species richness by extrapolation. BMC Ecol. 71:1195-1198.

PINHEIRO, P.C. 1999. Dinâmica das Comunidades de Peixes em Três Áreas Amostrais da Ilha do Mel, Baía de Paranaguá, Paraná, Brasil. Dissertação de Mestrado, Universidade Federal do Paraná.

PRIMER-E. 2004. Primer - Plymouth Routines in Multivariate Ecological Research. (Beta R3). PRIMER-E Ltd. Computer Program.

PUZZI, A. \& SILVA, M.R.G.A. 1981. Seletividade em Redes de Emalhar e Dimensionamento do Tamanho de Malha para a Captura da Corvina Micropogonias furnieri (Desmarest, 1823). Bol. Inst. Pesca, 8:139-156.

PUZZI, A., MOTA, A., CAMPOS, E.C. \& RODRIGUES, J.D. 1985. Considerações sobre alguns parâmetros biológico-pesqueiros de importância na captura da pescada-foguete, Macrodon ancylodon Bloch \& Schneider, 1801 (Percoidei, Sciaenidae), por rede de emalhe no litoral do estado de São Paulo. Bol. Inst. Pesca, 12(2):87-97.

ROCHA, M.L.C.F. 2009. Indicadores Ecológicos e Biomarcadores de Contaminação Ambiental na Ictiofauna da Baia de Santos e do Canal de Bertioga, São Paulo, Brasil. Tese de Doutorado, Instituto Oceanográfico, Universidade de São Paulo.

RODRIGUES, F.O., LAMPARELLI, C.C., MOURA, D.O. \& BRUNI, A.C. 1995. Os Manguezais da Baixada Santista: Uma Proposta de Classificação. Ecologia Brasiliensis, Volume I. Universidade Federal do Rio de Janeiro, Rio de Janeiro.
SANTOS, C., SCHWARZ JUNIOR, R., OLIVEIRA-NETO, J.F. \& SPACH, H.L.A. 2002. Ictiofauna em Duas Planícies de Maré do Setor Euhalino da Baía de Paranaguá, PR. Bol. Inst. Pesca, 28(1):49-60.

SANTOS, L.C.M., CUNHA-LIGNON, M. \& SCHAEFFER-NOVELLI, Y. 2007. Impacto do Petróleo no Manguezal do Rio Iriri (Baixada Santista, São Paulo): Diagnóstico da Cobertura Vegetal com Base em Fotografias Aéreas Digitais (1962-2003). In Anais do VIII Congresso de Ecologia do Brasil, Caxambu.

SÃO PAULO. Secretaria do Meio Ambiente, 2009. Fauna Ameaçada de Extinção no Estado de São Paulo. Governo de São Paulo, Fundação Parque Zoológico de São Paulo, São Paulo.

SCHAEFFER-NOVELLI, Y. \& CINTRON, G. 1986. Guia Para Estudo de Áreas de Manguezal - Estrutura, Função e Flora. Caribbean Ecological Research, São Paulo.

SCHAEFFER-NOVELLI, Y. 1991. Manguezais Brasileiros. Tese de Livre Docência. Instituto Oceanográfico, Universidade de São Paulo.

SILVA, R.C., VIANA, F.C., MAZZINI, F., SANTOS, P.E., QUINAGLIA, G.A. \& UMBUZEIRO, G.A. 2008. Avaliação Preliminar da Concentração de Chumbo e Cádmio em Sangue de Peixes (Mugil curema) da Baixada Santista. In 4o. Workshop em Gestão Integrada. São Paulo. http:// www1.sp.senac.br/hotsites/cas/workshopgestaointegrada/workshop_ programacao.htm.

VAZZOLER, A.E.M. 1969. Ictiofauna da Bahia de Santos. I. Sciaenidae (Percoidea, Percomorphi). Carpas. Doc. Tecnic, Rio de Janeiro 15:1-13.

VENDEL, A.L., LOPES, S.G., SANTOS, C. \& SPACH, H.L. 2003. Fish Assemblages in a Tidal Flat. Braz. Arch. Biol. Technol. 46(2):233-242. http://dx.doi.org/10.1590/S1516-89132003000200015 


\section{Apêndice}

Anexo I. Lista do material examinado, com: espécie, número de registro em coleção zoológica, número de exemplares, número da amostra de tecido e coordenadas geográficas.

Annex I. List of material examined with: species, registration number in zoological collection, number of individuals, number of tissues samples, and geographic coordinates.

Abudefduf saxatilis: LBP 10066, 2, (40579, 40586), 23 51’26,20” S e 4608’ 13,31” O.

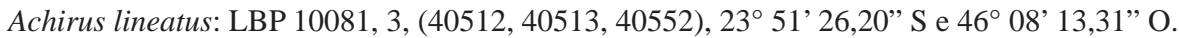

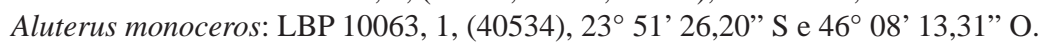

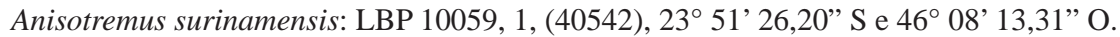

Aspistor luniscutis: LBP 10039, 2, (40502, 40526), 23 51’39, 31” S e 46 09'13,06” O.

Atherinella brasiliensis: LBP 10085, 4, (40562, 40563, 40621, 40622), 23 51' 26, 20” S e 460 08' 13,31” O.

Bagre bagre: LBP 10037, 1, (40597), 2351’26,20” S e 4608’13,31” O.

Bairdiella ronchus: LBP 10071, 2, (40524, 40530), 23 51’39,31” S e 460 09’13,06” O.

Bathygobius soporator: LBP 10077, 3, (40568, 40569, 40571), 23 52' 55,67” S e 46 10' 07,20” O.

Caranx latus: LBP 10055, 5, (40535, 40536, 40537, 40585, 40591), 2351’26,20” S e 4608' 13,31” O.

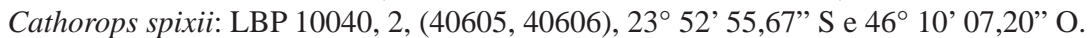

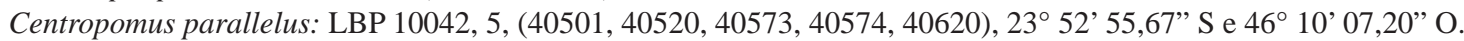

Centropomus undecimalis: LBP 10043, 1, (40602), 23 52' 55,67”' S e 46 10’ 07,20” O.

Chaetodipterus faber: LBP 10056, 2, (40510, 40518), 23 51'39,31” S e 460 09'13,06” O.

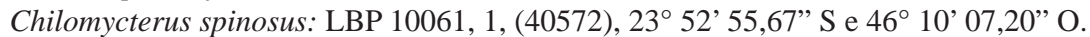

Citharichthys spilopterus: LBP 10075, 3, (40505, 40550, 40551), 2351'26,20” S e 4608' 13,31” O.

Cynoscion acoupa: LBP 10049, 1, (40599), 2351'39,31” S e 4609’13,06” O.

Cynoscion microlepidotus: LBP 10041, 1, (40588), 23 51’39,31” S e 4609'13,06” O.

Diapterus rhombeus: LBP 10078, 2, (40508, 40531), 2352'55,67’'S e 46¹0’07,20”O.

Diplectrum radiale: LBP 10069, 3, (40543, 40544, 40545), 2351’26, $20^{\prime}$ ' S e 4608’ 13,31” O.

Diplodus argenteus: LBP 10068, 1, 221, (40577), 23 51’26,20” S e 4608’13,31” O.

Etropus crossotus: LBP 10088, 1, (40517), 2352' 55,67” S e 46 10’ 07,20” O.

Genidens genidens: LBP 10038, 6, (40525, 40529, 40540, 40556, 40603, 40604), 23 52’ 55,67” S e 46 $10^{\prime} 07,20^{\prime \prime} \mathrm{O}$.

Genyatremus luteus: LBP 10033, 1, (40601), 23 51’26,20” S e 4608' 13,31” O.

Haemulon steindachneri: LBP 10058, 4, (40607, 40608, 40581, 40582), 23 51' 26,20” S e 46 08' 13,31" O.

Harengula clupeola: LBP 10064, 8, (40547, 40548, 40549, 40580, 40623, 40624, 40625, 40626), 2351' $26,20^{\prime \prime}$ S e 4608' $13,31^{\prime \prime}$ O.

Hemicaranx amblyrhynchus: LBP 10054, 1, (40595), 23 51'26,20” S e 4608' 13,31” O.

Isopisthus parvipinnis: LBP 10072, 1, (40600), 23 51'39,31”' S e 4609' $13,06^{\prime \prime} \mathrm{O}$.

Kyphosus saltatrix: LBP 10048, 2, (40575, 40576), 23 51’26,20”' S e 460 08’13,31” O.

Lagocephalus laevigatus: LBP 10087, 1, (40532), 2351'39,31” S e 4609'13,06” O.

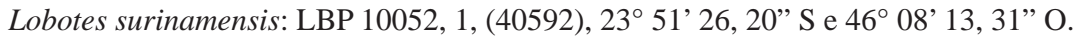

Lycengraulis grossidens: LBP 10065, 2, (40507, 40584), 2351'26, 20” S e 4608' 13,31” O.

Menticirrhus americanus: LBP 10073, 2, (40519, 40561), 2351'26,20” S e 460 08'13,31” O.

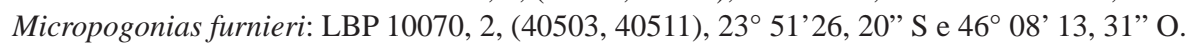

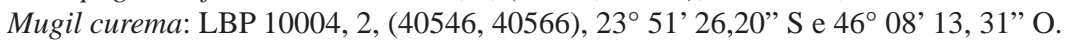

Mugil liza: LBP 10051, 6, (40506, 40557, 40558, 40559, 40560, 40589), 23 52’ 55,67” S e 46 10’ 07,20” O.

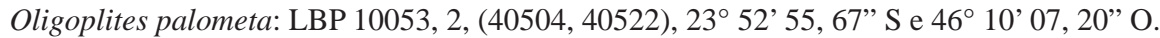

Peprilus paru: LBP 10045, 2, (40593, 40594), 2351’26,20” S e 4608’13, 31” O.

Polydactylus virginicus: LBP 10060, 2 (40523,40533), 23 51’26, 20” S e 4608' 13,31 ”O.

Pomatomus saltatrix: LBP 10082, 8, (40619, 40611, 40612, 40614, 40615, 40616, 40617, 40618), 23 51' 26, $20^{\prime \prime}$ S e 4608’ 13 , 31” O.

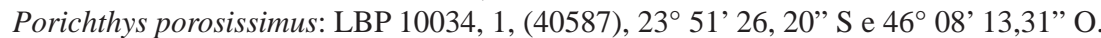

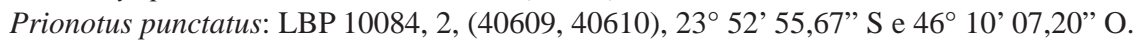

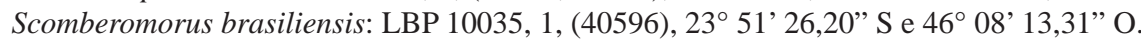

Selene setapinnis: LBP 10083, 2, (40527, 40528), 23 51'39, 31 ”S e 4609' 13,06” O.

Selene vomer: LBP 10046, 1, (40578), 2351’26,20” S e 4608’13, 31” O.

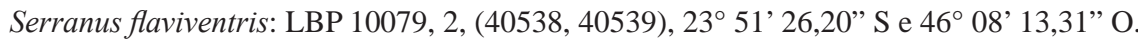

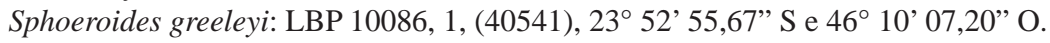

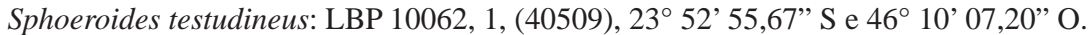

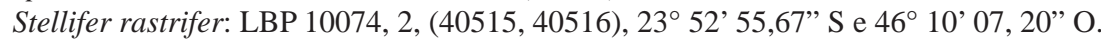

Strongylura timucu: LBP 10057, 1, (40613), 23 51' 26,20” S e 460 08' 13,31” O.

Symphurus tessellatus: LBP 10076, 1, (40514), 23 51' 26,20” S e 460 08' 13,31” O.

Trachinotus carolinus: LBP 10067, 1, (40564), 23 51' 26,20” S e 460 08' 13,31” O.

Trachinotus falcatus: LBP-10044, 4, (40553, 40554, 40555, 40583), 23 51'26, 20” S e 4608' 13,31 ” O.

Trichiurus lepturus: LBP 10036, 2, (40521, 40598), 2351’26,20” S e 4608’ 13,31” O. 